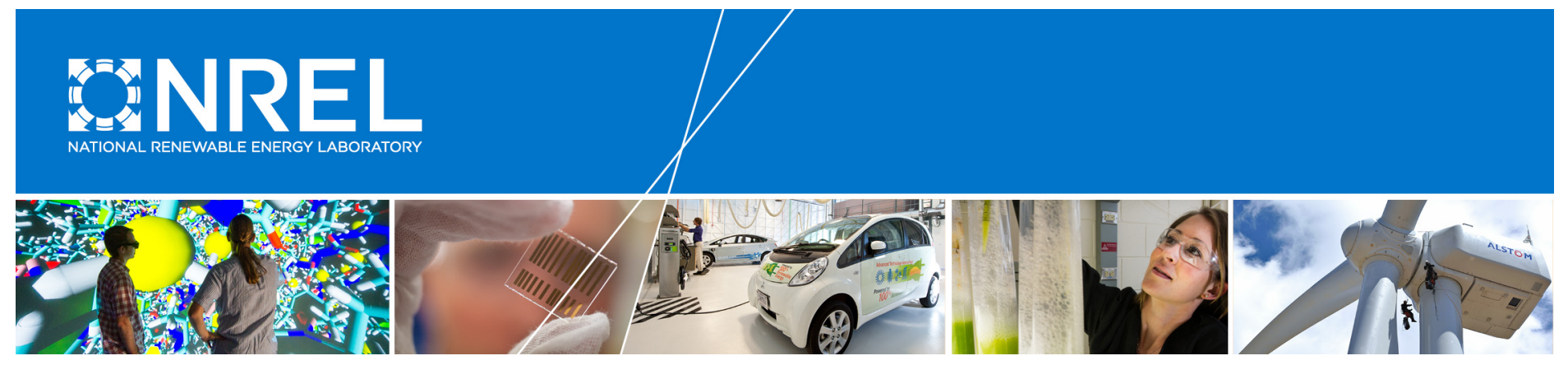

\title{
NREL Topic 1 Final Report: \\ Cohesive Application of Standards-Based Connected Devices to Enable Clean Energy Technologies
}

Andrew Hudgins, Bethany Sparn, and Xin Jin National Renewable Energy Laboratory

Brian Seal

Electric Power Research Institute

NREL is a national laboratory of the U.S. Department of Energy Office of Energy Efficiency \& Renewable Energy Operated by the Alliance for Sustainable Energy, LLC

This report is available at no cost from the National Renewable Energy Laboratory (NREL) at www.nrel.gov/publications.

Technical Report

NREL/TP-5B00-70274

February 2018 


\title{
NREL Topic 1 Final Report: Cohesive Application of Standards-Based Connected Devices to Enable Clean Energy Technologies
}

\author{
Andrew Hudgins, Bethany Sparn, and Xin Jin \\ National Renewable Energy Laboratory \\ Brian Seal \\ Electric Power Research Institute
}

\section{Suggested Citation}

Hudgins, Andrew, Sparn, Bethany, Jin, Xin, Seal, Brian. NREL Topic 1 Final Report: Cohesive Application of Standards-Based Connected Devices to Enable Clean Energy Technologies. Golden, CO: National Renewable Energy Laboratory. NREL/TP-5B00-70274.

NREL is a national laboratory of the U.S. Department of Energy Office of Energy Efficiency \& Renewable Energy Operated by the Alliance for Sustainable Energy, LLC

This report is available at no cost from the National Renewable Energy Laboratory (NREL) at www.nrel.gov/publications.

National Renewable Energy Laboratory 15013 Denver West Parkway

Golden, CO 80401

303-275-3000 • www.nrel.gov

\section{Technical Report}

NREL/TP-5B00-70274

February 2018

Contract No. DE-AC36-08GO28308 


\title{
This publication was reproduced from the best available copy submitted by the subcontractor and received no editorial review at NREL.
}

\begin{abstract}
NOTICE
This report was prepared as an account of work sponsored by an agency of the United States government. Neither the United States government nor any agency thereof, nor any of their employees, makes any warranty, express or implied, or assumes any legal liability or responsibility for the accuracy, completeness, or usefulness of any information, apparatus, product, or process disclosed, or represents that its use would not infringe privately owned rights. Reference herein to any specific commercial product, process, or service by trade name, trademark, manufacturer, or otherwise does not necessarily constitute or imply its endorsement, recommendation, or favoring by the United States government or any agency thereof. The views and opinions of authors expressed herein do not necessarily state or reflect those of the United States government or any agency thereof.
\end{abstract}

This report is available at no cost from the National Renewable Energy Laboratory (NREL) at www.nrel.gov/publications.

Available electronically at SciTech Connect http:/www.osti.gov/scitech

Available for a processing fee to U.S. Department of Energy and its contractors, in paper, from:

U.S. Department of Energy

Office of Scientific and Technical Information

P.O. Box 62

Oak Ridge, TN 37831-0062

OSTI http://www.osti.gov

Phone: 865.576.8401

Fax: 865.576.5728

Email: reports@osti.gov

Available for sale to the public, in paper, from:

U.S. Department of Commerce

National Technical Information Service

5301 Shawnee Road

Alexandria, VA 22312

NTIS http://www.ntis.gov

Phone: 800.553 .6847 or 703.605 .6000

Fax: 703.605.6900

Email: orders@ntis.gov 


\section{Abstract}

This document is the final report of a two-year development, test, and demonstration project entitled "Cohesive Application of Standards-Based Connected Devices to Enable Clean Energy Technologies". The project was part of the National Renewable Energy Laboratory's (NREL) Integrated Network Test-bed for Energy Grid Research and Technology (INTEGRATE) initiative. Specifically, this project is a component of RFP Number RCS-4-42326, Topic 1 ,“Connected Devices".

The Electric Power Research Institute (EPRI) and a team of partners were selected by NREL to carry out a project to develop and test how smart, connected consumer devices can act to enable the use of more clean energy technologies on the electric power grid. The project team includes a set of leading companies that produce key products in relation to achieving this vision: thermostats, water heaters, pool pumps, solar inverters, electric vehicle supply equipment, and battery storage systems.

A key requirement of the project was open access at the device level - a feature seen as foundational to achieving a future of widespread distributed generation and storage. The internal intelligence, standard functionality and communication interfaces utilized in this project result in the ability to integrate devices at any level, to work collectively at the level of the home/business, microgrid, community, distribution circuit or other. Collectively, the set of products serve as a platform on which a wide range of control strategies may be developed and deployed. 


\section{Table of Contents}

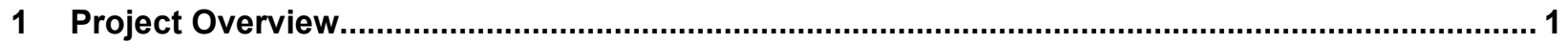

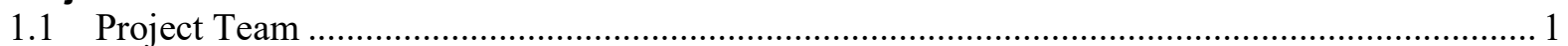

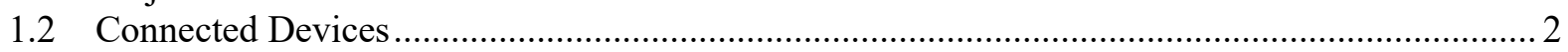

1.2.1 Siemens Electric Vehicle Supply Equipment (EVSE) ............................................ 2

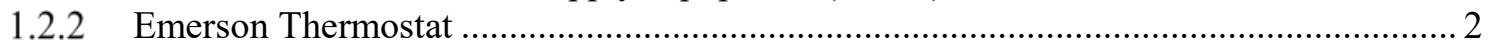

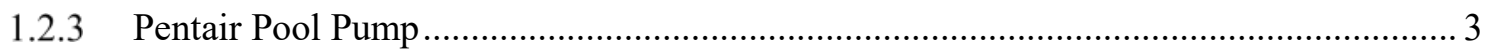

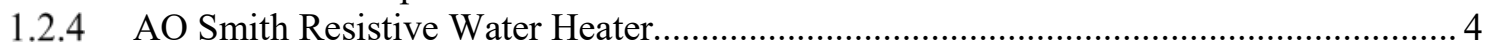

1.2.5 AO Smith Heat Pump Water Heater ...................................................................... 4

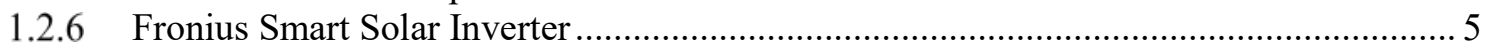

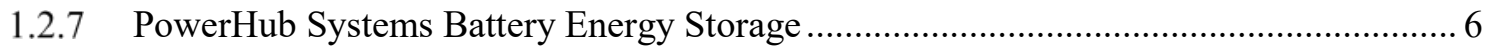

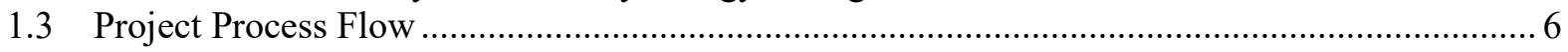

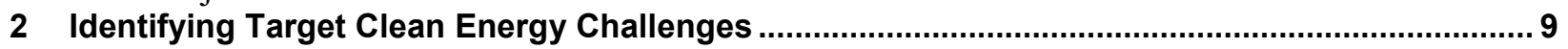

3 Determining Connected Device Functionality ..................................................................... 11

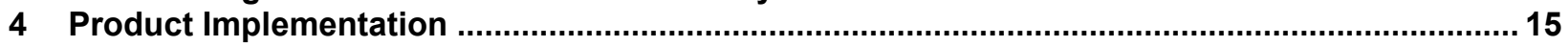

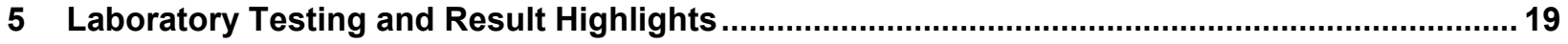

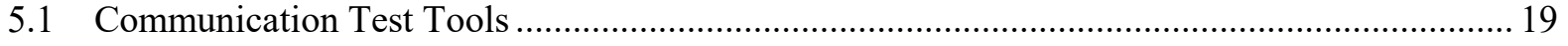

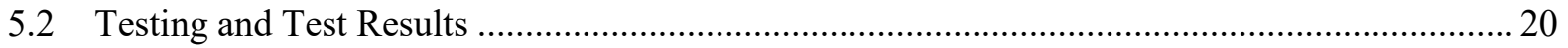

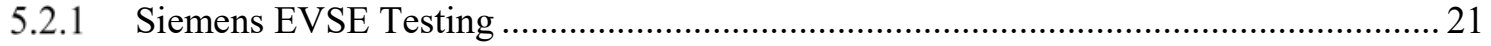

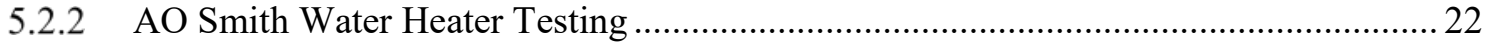

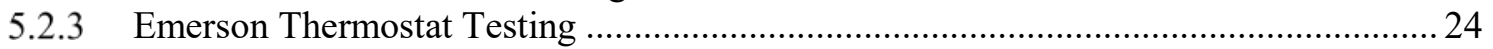

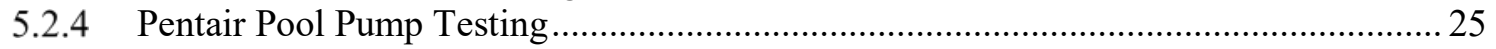

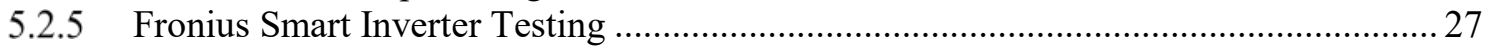

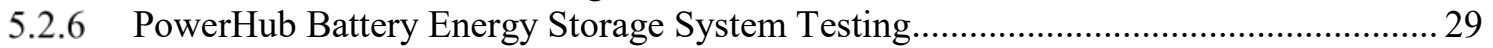

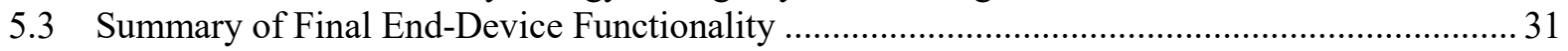

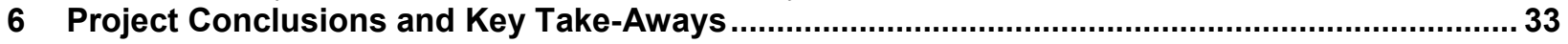




\section{List of Figures}

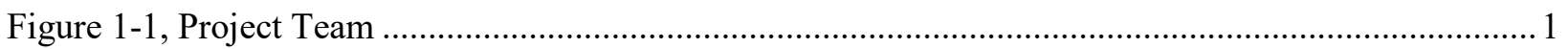

Figure 1-2, Overall Project Process and Deliverables .................................................................. 7

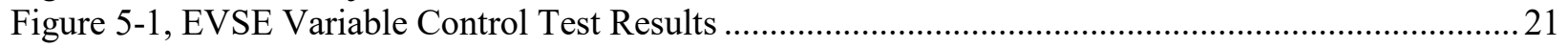

Figure 5-2, Resistive Water Heater Curtailment Function Test Results ................................................. 23

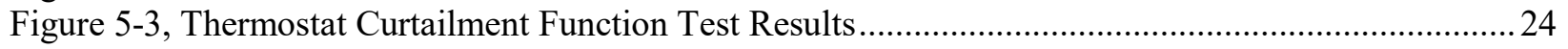

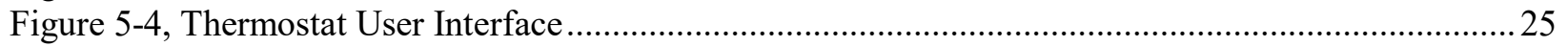

Figure 5-5, Pool Pump Smart Shed Response Test Results..............................................................26

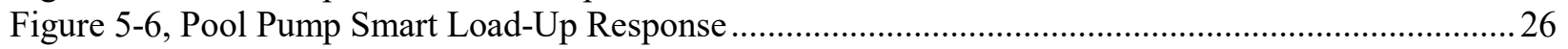

Figure 5-7, Pool Pump Variable Speed Control Test Results ................................................................2 27

Figure 5-8, Solar Inverter Volt-Var Function ................................................................................... 28

Figure 5-9, Solar Inverter Power Factor Function Measured (solid lines) vs. Ideal (dashed lines)........... 29

Figure 5-10, Battery System Charge/Discharge Function ..................................................................... 30

Figure 5-11, Battery System Frequency-Watt Function ........................................................................ 31 


\section{List of Tables}

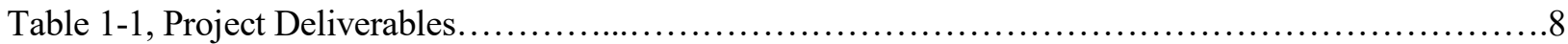

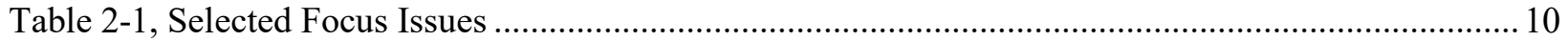

Table 3-1, Summary of Device Functionality for High Penetration Grid Issues ..................................... 12

Table 4-1, Device Open Standard Communication Interfaces............................................................. 19

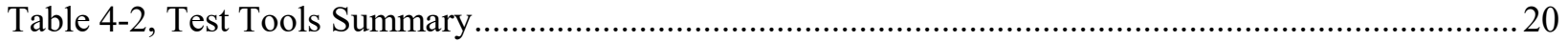

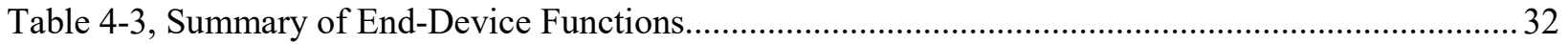




\section{Project Overview}

This document is the final report of a two year development, test, and demonstration project entitled "Cohesive Application of Standards-Based Connected Devices to Enable Clean Energy Technologies". This project was part of the National Renewable Energy Laboratory's (NREL) Integrated Network Test-bed for Energy Grid Research and Technology (INTEGRATE) initiative. Specifically, this project is a component of RFP Number RCS-4-42326, Topic 1, "Connected Devices".

The Electric Power Research Institute (EPRI) and a team of partners were selected by NREL to carry out a project that developed and tested means by which smart, connected consumer devices can act to enable the use of more clean energy technologies on the electric power grid. In the context of this report, "smart" responses refer to those in which the connected device manages its behavior in response to received signals, intelligently providing the maximum response levels and durations possible while ensuring that its core mission is achieved and that customer comfort and safety are maintained.

A requirement of the project was open communication access at the device level $-\mathrm{a}$ feature seen as foundational to achieving the future vision of widespread distributed generation and storage. The internal intelligence, standard functionality and communication interfaces utilized in this project result in the ability to integrate devices at any level, and to work collectively at the level of the home/business, microgrid, community, or distribution circuit.

\subsection{Project Team}

The project team and organization is identified in Figure 1-1. The team included leading manufacturers of residential load types with potential to play a prominent role in energy management and demand response. Additionally, a group of utility representatives served as a technical advisory group to identify limiting factors for distribution-connected solar PV and to review the mitigating actions identified for each end device type.

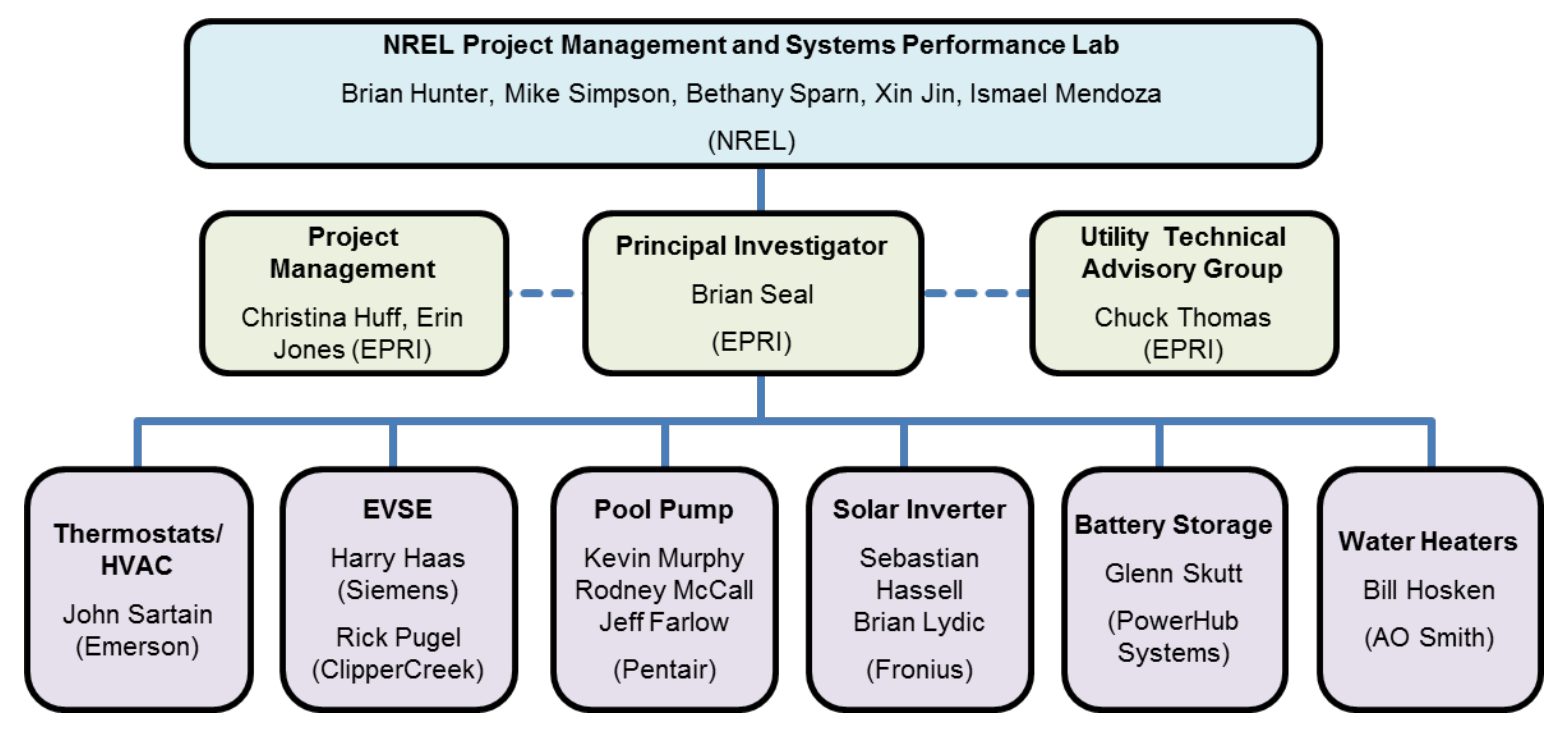

Figure 1-1. Project Team 


\subsection{Connected Devices}

The representative set of devices identified in the following sections were utilized in the project. As noted previously, each had open standard communication interfaces so that they could be integrated into any communication control system, locally and remotely.

\subsubsection{Siemens Electric Vehicle Supply Equipment (EVSE)}

\begin{tabular}{|l|l|}
\hline \multicolumn{1}{|c|}{ Parameter } & \multicolumn{1}{c|}{ Value } \\
\hline Manufacturer & Siemens \\
\hline Model & VersiCharge SG-2 \\
\hline Rating & $30[\mathrm{~A}]$ \\
\hline Supporting Equipment & $\begin{array}{l}\text { Electric Vehicle Scion } \\
\text { iQev }\end{array}$ \\
\hline Communication Protocol & CTA-20451 \\
\hline Final Production Readiness & $\begin{array}{l}\text { UL Certified, Ready for } \\
\text { Commercialization }\end{array}$ \\
\hline
\end{tabular}

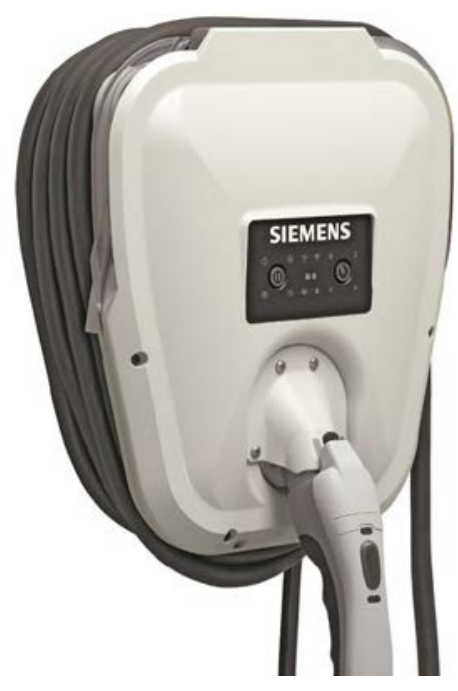

\subsubsection{Emerson Thermostat}

\begin{tabular}{|l|l|}
\hline \multicolumn{1}{|c|}{ Parameter } & \multicolumn{1}{c|}{ Value } \\
\hline Manufacturer & Emerson \\
\hline Model & 1F98-0651 \\
\hline Rating & \\
\hline Supporting Equipment & Goodman HVAC \\
\hline Communication Protocol & CTA-2045 \\
\hline Final Production Readiness & Ready for Commercialization \\
\hline
\end{tabular}

\footnotetext{
${ }^{1}$ Note: During the course of this project, the Consumer Electronics Association changed its name to the Consumer Technology Association. Accordingly, the CEA-2045 standard was renamed the CTA-2045 standard and is herein referred-to as such.
} 


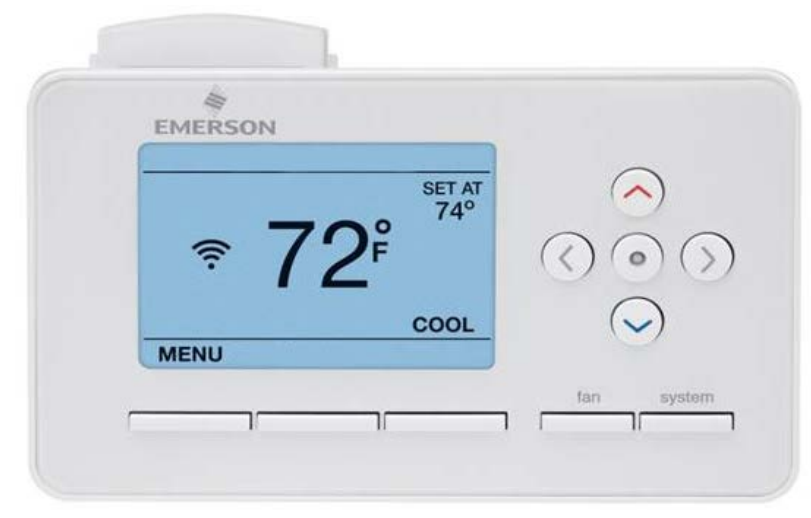

\subsubsection{Pentair Pool Pump}

\begin{tabular}{|l|l|}
\hline \multicolumn{1}{|c|}{ Manufacturer } & \multicolumn{1}{c|}{ Pentair } \\
\hline Model & $\begin{array}{l}\text { Connected Demand Response } \\
\text { Controller* and IntelliFlo VS-3050 } \\
\text { Pump }\end{array}$ \\
\hline Rating & Variable 0-3000[W] \\
\hline Supporting Equipment & Closed Loop Circulation System \\
\hline Communication Protocol & CTA-2045 \\
\hline Final Production Readiness & $\begin{array}{l}\text { UL Certified, Ready for } \\
\text { Commercialization }\end{array}$ \\
\hline
\end{tabular}

*Note: The controller works with multiple pump models

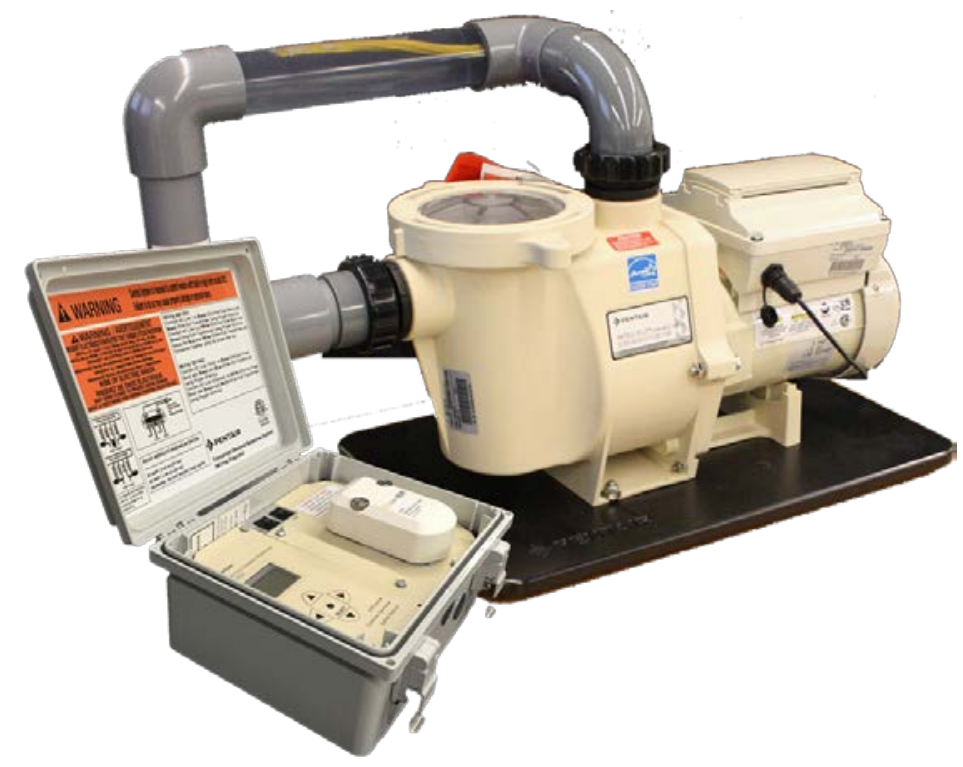




\subsubsection{AO Smith Resistive Water Heater}

\begin{tabular}{|l|l|}
\hline \multicolumn{1}{|c|}{ Parameter } & \multicolumn{1}{c|}{ Value } \\
\hline Manufacturer & AO Smith \\
\hline Model & PXNT \\
\hline Rating & 50[gal], 5500[W] \\
\hline Supporting Equipment & N/A \\
\hline Communication Protocol & CTA-2045 \\
\hline Final Production Readiness & $\begin{array}{l}\text { UL Certified, Ready for } \\
\text { Commercialization }\end{array}$ \\
\hline
\end{tabular}

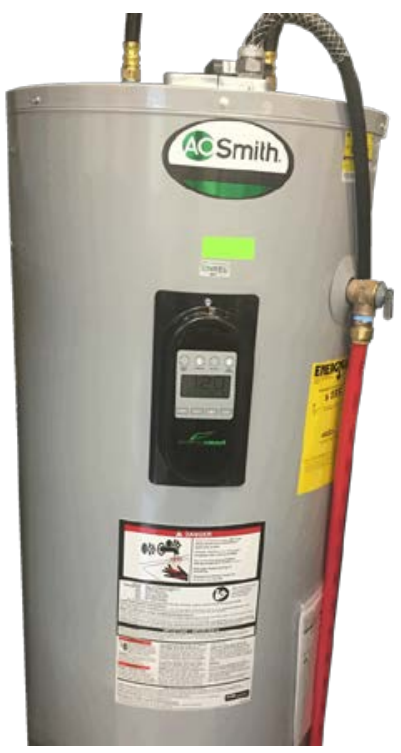

\subsubsection{AO Smith Heat Pump Water Heater}

\begin{tabular}{|l|l|}
\hline \multicolumn{1}{|c|}{ Parameter } & \multicolumn{1}{c|}{ Value } \\
\hline Manufacturer & AO Smith \\
\hline Model & SHPT \\
\hline Rating & 50[gal] \\
\hline Supporting Equipment & N/A \\
\hline Communication Protocol & CTA-2045 \\
\hline Final Production Readiness & $\begin{array}{l}\text { UL Certified, Ready for } \\
\text { Commercialization }\end{array}$ \\
\hline
\end{tabular}




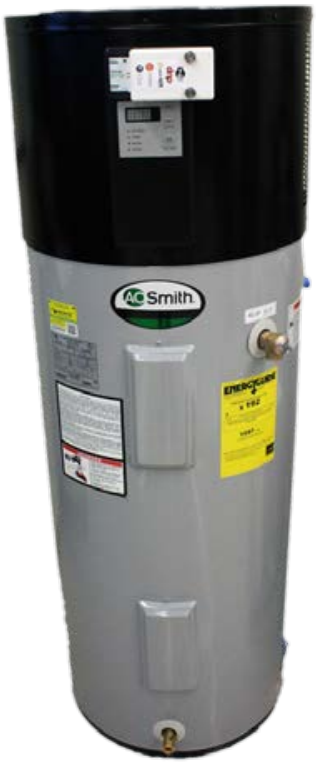

1.2.6 Fronius Smart Solar Inverter

\begin{tabular}{|l|l|}
\hline \multicolumn{1}{|c|}{ Parameter } & \multicolumn{1}{c|}{ Value } \\
\hline Manufacturer & Fronius \\
\hline Model & IG Plus Advanced \\
\hline Rating & $3000[W]$ \\
\hline Supporting Equipment & $\begin{array}{l}\text { Grid Simulator, PV } \\
\text { Simulator }\end{array}$ \\
\hline Communication Protocol & SunSpec \\
\hline Final Production Readiness & Not UL Certified \\
\hline
\end{tabular}

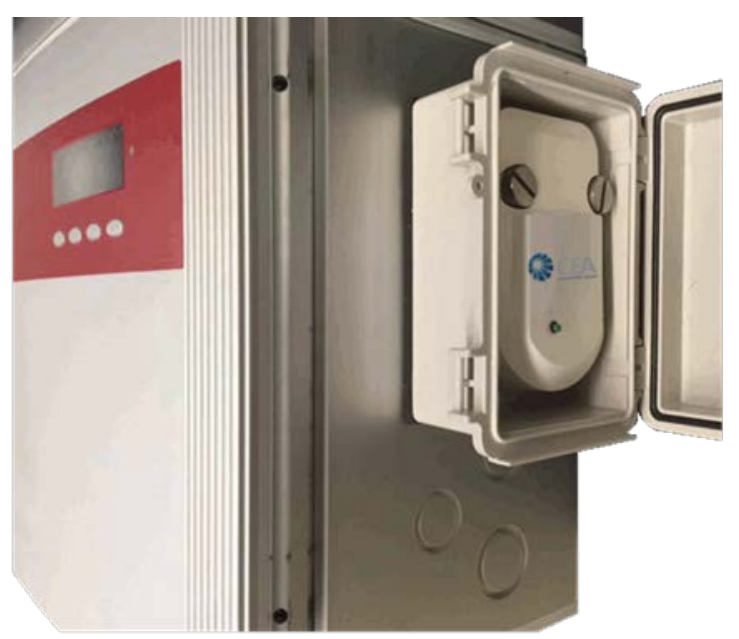




\subsubsection{PowerHub Systems Battery Energy Storage}

\begin{tabular}{|l|l|}
\hline \multicolumn{1}{|c|}{ Parameter } & \multicolumn{1}{c|}{ Value } \\
\hline Manufacturer & PowerHub Systems \\
\hline Model & CE 3034 \\
\hline Rating & 30KVA, 34KWh \\
\hline Supporting Equipment & Grid Simulator \\
\hline Communication Protocol & DNP3, SunSpec \\
\hline Final Production Readiness & $\begin{array}{l}\text { Designed to UL 1741 requirements, tested } \\
\text { per IEEE 1547, Commercialization Ready }\end{array}$ \\
\hline
\end{tabular}

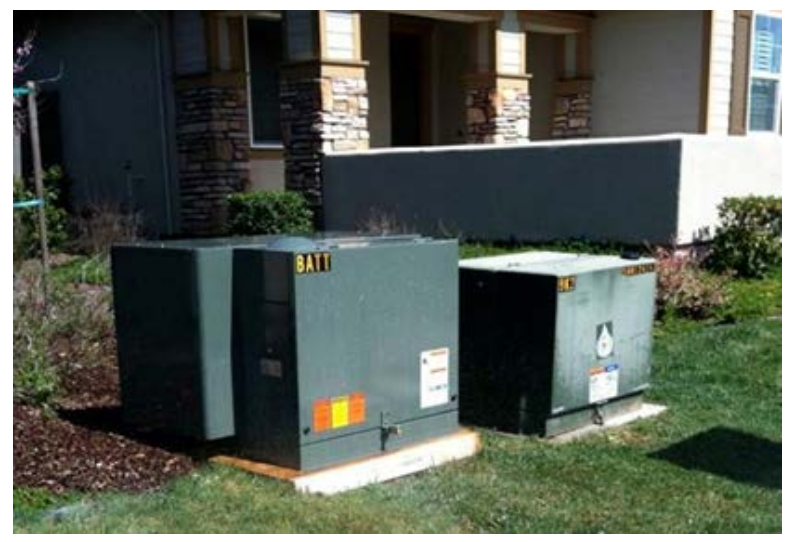

\subsection{Project Process Flow}

The primary steps involved in the project are identified in flowchart of Figure 1-2, and described throughout this report. The numbered circles indicate the deliverables, which are listed in Table 1-1 following.

The first step in the project was to identify a set of primary issues limiting solar PV deployment on distribution circuits. Based on these issues, an assessment was performed for each product type to identify the ways each might act to help mitigate each issue.

The list of actions that each device could perform became the design goal for the manufacturers as the features were implemented. The list of device actions also served as a guide to develop the laboratory test plans for each product.

When the designs were completed, prototypes were produced, installed in the NREL laboratory and tested. To support this testing, EPRI produced and provided PC-based test software and interface cables. The project resulted in the range of deliverables identified in Table 1-1, including in addition to this report the device utilization summary, test plans, functional devices (which remain installed in the System Performance Laboratory (SPL) at NREL), and detailed test results. 


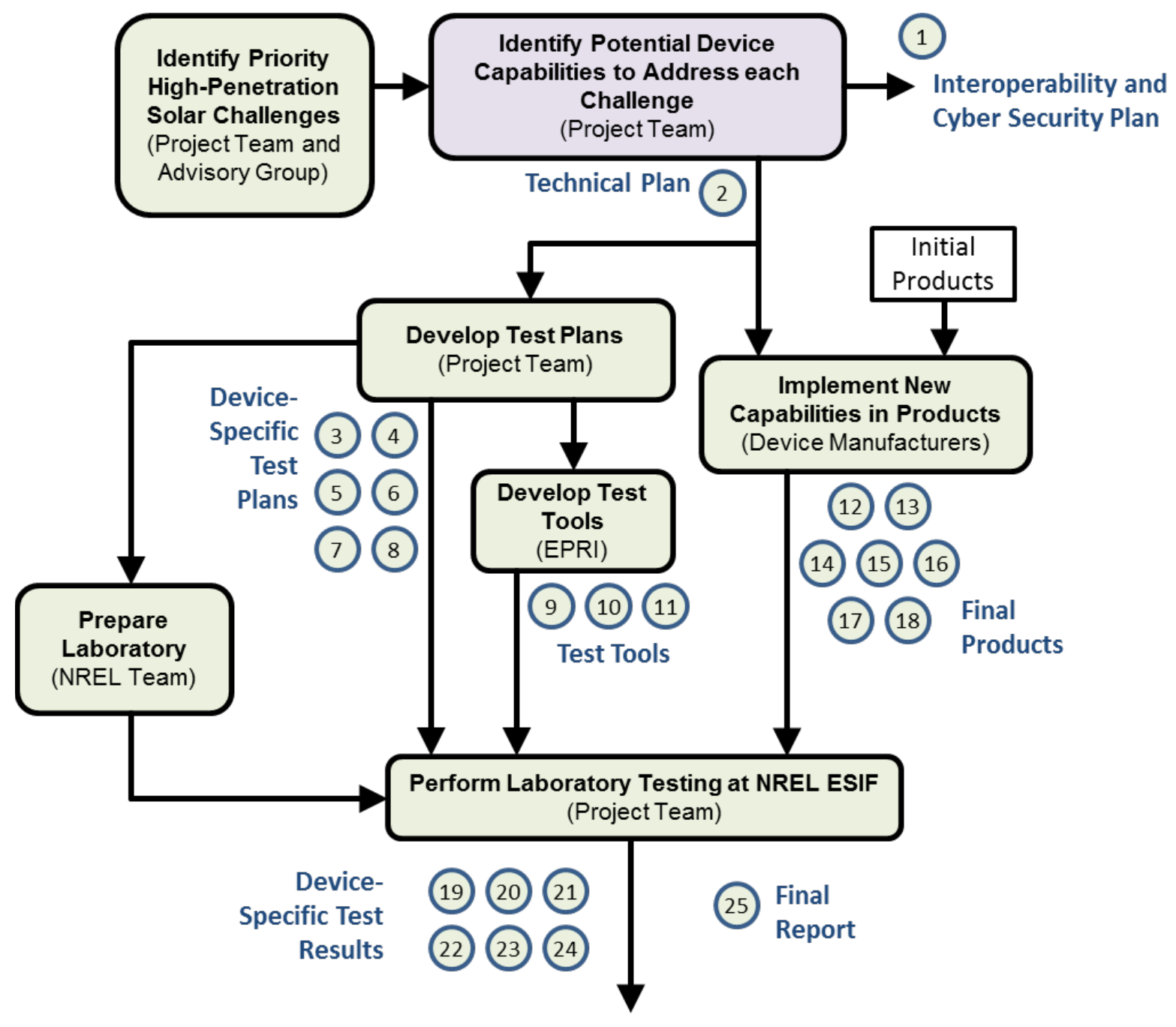

Figure 1-2. Overall Project Process and Deliverables 
Table 1-1. Project Deliverables

\begin{tabular}{|c|c|c|}
\hline $\begin{array}{c}\text { Deliverable } \\
\text { Number }\end{array}$ & Title & Description \\
\hline 1 & Interoperability and Cyber Security Plan & Technical Document \\
\hline 2 & Utilization of Connected Devices & Technical Document \\
\hline 3 & Thermostat Test Plan & Test Plan \\
\hline 4 & Water Heater Test Plan & Test Plan \\
\hline 5 & Pool Pump Test Plan & Test Plan \\
\hline 6 & EVSE Test Plan & Test Plan \\
\hline 7 & Solar Inverter Test Plan & Test Plan \\
\hline 8 & Battery Storage Test Plan & Test Plan \\
\hline 9 & SunSpec Test Software & Software \\
\hline 10 & EPRI CTA-2045 Simulator & Software \\
\hline 11 & EPRI Interface Test Cables & Hardware \\
\hline 12 & AO Smith Resistive Water Heater & Final Product \\
\hline 13 & AO Smith Heat Pump Water Heater & Final Product \\
\hline 14 & Emerson Thermostat & Final Product \\
\hline 15 & Siemens EVSE & Final Product \\
\hline 16 & Pentair Pool Pump & Final Product \\
\hline 17 & Fronius Solar Inverter & Final Product \\
\hline 18 & PowerHub Battery Storage System & Final Product \\
\hline 19 & Thermostat Test Results & Test Data/Results \\
\hline 20 & Water Heater Test Results & Test Data/Results \\
\hline 21 & Pool Pump Test Results & Test Data/Results \\
\hline 22 & EVSE Test Results & Test Data/Results \\
\hline 23 & Solar Inverter Test Results & Test Data/Results \\
\hline 24 & Battery Storage Test Results & Test Data/Results \\
\hline 25 & Final Report & Technical Document \\
\hline
\end{tabular}




\section{Identifying Target Clean Energy Challenges}

The project team and Technical Advisory Group (TAG) began the project by identifying limiting factors for connecting high-levels of distributed energy resources (DER) on distribution circuits. Based on the experiences of the group, a wide range of factors were identified including:

- Power system level at which the issue manifests

- Ubiquity of locations where the issue is likely to manifest

- Penetration level of DER required to cause the issue

- Type of DER technology that creates the problem

- Impact/severity of problems that result

- Anticipated timeline of appearance of each issue

- Relation to the connected devices of this project

Through the assessment, the six high penetration issues identified in Table 2-1 were selected as the focus for the connected device developments and testing to follow. 
Table 2-2. Selected Focus Issues

\begin{tabular}{|c|c|}
\hline $\begin{array}{l}\text { High } \\
\text { Penetration } \\
\text { Issues }\end{array}$ & Issue Description \\
\hline $\begin{array}{l}\text { Residential } \\
\text { Transformer } \\
\text { Loading }\end{array}$ & $\begin{array}{l}\text { Peak load on residential transformers exceeding ratings due to reverse power } \\
\text { flow. This issue specifically related to solar generation, peaking at mid-day } \\
\text { when loads may be low due to unoccupied premises or mild weather. }\end{array}$ \\
\hline $\begin{array}{l}\text { Customer/ } \\
\text { Secondary } \\
\text { Overvoltage }\end{array}$ & $\begin{array}{l}\text { Over voltage caused locally on the customer side of a distribution transformer } \\
\text { due to local PV generation. This may be caused by a number of factors, } \\
\text { including local transformer ratios/tap positions and the significant impedance of } \\
\text { the transformer and low-voltage secondary circuit. }\end{array}$ \\
\hline $\begin{array}{l}\text { Distribution } \\
\text { Circuit } \\
\text { Overvoltage }\end{array}$ & $\begin{array}{l}\text { Over voltage on the medium voltage distribution circuit caused by large DER } \\
\text { plants or the aggregate effect of many small DER. }\end{array}$ \\
\hline $\begin{array}{l}\text { Over } \\
\text { Generation Risk }\end{array}$ & $\begin{array}{l}\text { Mid-day and nighttime need for other forms of generation being low (due to } \\
\text { high levels of wind or PV and low demand), resulting in the need to reduce } \\
\text { base-load generation which cannot be restarted quickly. This issue was } \\
\text { defined and described from the perspective of the system operator, the entity } \\
\text { balancing generation with demand in a given region. It is assumed that the } \\
\text { local generator is unaware, or has little local awareness that this issue is } \\
\text { occurring unless a signal is sent. The device functionalities identified to } \\
\text { address this issue relate to potential responses to such signals, sent from the } \\
\text { system operator to prevent base-load generation (which may not be able to } \\
\text { shutdown or restarted quickly) from exceeding demand. This issue was } \\
\text { addressed as one that occurs on a daily basis. }\end{array}$ \\
\hline $\begin{array}{l}\text { Fast Ramp } \\
\text { Needs }\end{array}$ & $\begin{array}{l}\text { Need for a fast increase in other forms of generation late in the day when the } \\
\text { sun is setting (or when wind is dying) and demand is high. This issue is } \\
\text { described from the perspective of the system operator. It relates to periods } \\
\text { when the system demand is increasing sharply (due to declines in renewable } \\
\text { generation) and the system operator's resources cannot ramp-up fast enough. } \\
\text { Without a signal send from the system operator, there may be no evidence } \\
\text { (e.g. frequency, voltage) at the local solar PV system that this issue is } \\
\text { occurring. This issue was addressed as one that occurs on a daily basis. }\end{array}$ \\
\hline $\begin{array}{l}\text { Excess } \\
\text { Renewable } \\
\text { Generation }\end{array}$ & $\begin{array}{l}\text { Periods of time when the quantity of available renewable generation (e.g. wind, } \\
\text { solar) exceeds that which the grid can accept. This issue was defined and } \\
\text { described from the point of view of the solar generation owner. Their resource } \\
\text { is being limited due to the grid's inability to take the power, potentially reducing } \\
\text { their income/benefit. This issue is differentiated from "Over Generation Risk" } \\
\text { in that the generation systems may have local evidence in the form of voltage } \\
\text { or frequency, that the grid cannot accept their power. It is also differentiated } \\
\text { by the expectation that occurrences are infrequent (rather than daily) and the } \\
\text { unpredictability of time of occurrence. }\end{array}$ \\
\hline
\end{tabular}




\section{Determining Connected Device Functionality}

For each of the priority issues, the project team assessed the connected products to determine what functions each could provide to help mitigate the issue. The outcome of these assessments became the design goal for each product. In this sense, the project was inherently practical. In other words, the concepts identified in this step had to be production-viable because they were to be implemented in the next step.

Accordingly, five principles were identified to guide this step:

- Product Cost -Possible vs. Practical. The scope was limited to device capabilities that could be mass-market viable going forward, not adding substantial cost to the product. As an example, it was noted that water heaters could have mixing valves that would enable the internal tank temperatures to be run higher and therefore the product to store more energy. But because such valves represent a substantial cost addition, they were not included in the products developed for this project.

- Consumer Choice - Adjustable Responses. To the extent possible, the approach and standards used would allow for consumers and device manufacturers to determine the aggressiveness, extent, duration and frequency of responses.

- Consumer Choice - Opt Out/Override. The product designs and standards used would allow the consumer to override events.

- Avoiding Device Specific Commands. In keeping with industry demand response standards, the approach would use messages that are (to the extent possible) independent of the type of device. In other words, the messages used could be applied to a wide range of end device types. The standards used in this project (CTA-2045, SunSpec, and DNP3) include support for certain device-specific and even manufacturer-specific commands, but these were avoided in this project.

- Privacy and Remote Visibility. The approach would honor consumer privacy. While the TAG recognized that status monitoring is a necessity, the approach and standards used would, to the extent possible, be architecture-agnostic so that consumers could have choice in how their devices are connected. For example, the load devices were equipped with the modular CTA-2045 interface. This interface allows for devices to be locallyconnected and managed via a local home/facility energy management system. In this way, end-use devices may provide the grid support and solar compensation needed, but without a pathway for an outside entity to observe the consumer's actions.

The detailed description of the functionality identified for each issue and device was documented and published separately in the report: "Utilization of Connected Devices to Enable Clean Energy Technologies”. Table 3-1 provides a summary. Although some issues are similar, the recommended actions for each end-device type differ for a number of reasons. For example, an overvoltage grid condition that rarely occurs may reasonably be addressed by reducing solar generation whereas the same overvoltage condition, but due to a cause that may occur daily is addressed some other way. Factors involved in selecting these device actions include:

- The frequency with which a given grid issue is likely to occur, such as daily vs a few times a year 
- The duration for which a given grid issue is likely to occur, such as several hours vs several minutes

- The predictability (e.g. time of day) of a given grid issue such that scheduled actions may be considered

- The scale of a given grid issue (whether it is local or widespread)

- The inherent visibility of a given grid issue to the end-device. For example, a device may directly observe a frequency error, but does not know the Area Control Error without communication

Table 3-3. Summary of Device Functionality for High Penetration Grid Issues

\begin{tabular}{|c|c|c|}
\hline $\begin{array}{l}\text { Grid } \\
\text { Issue }\end{array}$ & Device Type & Summary of Selected Device Actions* \\
\hline \multirow{6}{*}{ 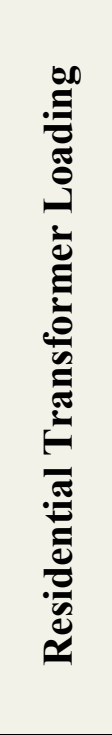 } & EVSE & No actions are recommended for this device $\&$ issue. \\
\hline & Thermostat & No actions are recommended for this device $\&$ issue. \\
\hline & Pool Pump & $\begin{array}{l}\text { - Scheduled operation } \\
\text { - Increase consumption during periods of need } \\
\text { - Monitoring real power level }\end{array}$ \\
\hline & $\begin{array}{l}\text { Battery } \\
\text { Storage }\end{array}$ & $\begin{array}{l}\text { - Autonomously reduce generation power level in response to higher local voltages } \\
\text { - Scheduled operation to store energy during midday } \\
\text { - Configured operation to limit reverse power flow based on measurement } \\
\text { - Remote operation to initiate specific charge/discharge instances } \\
\text { - Monitoring real power level }\end{array}$ \\
\hline & $\begin{array}{c}\text { Smart } \\
\text { Inverter }\end{array}$ & $\begin{array}{l}\text { - Dispatchable limiting of generation during periods of need (last resort) } \\
\text { - Monitoring real power generation level }\end{array}$ \\
\hline & Water Heater & $\begin{array}{l}\text { - Avoiding water heating ahead of events to enhance capability then heating during } \\
\text { periods of reverse power flow } \\
\text { - Monitoring of present power level } \\
\text { - Monitoring of the device's thermal condition and associated ability to use energy }\end{array}$ \\
\hline \multirow{6}{*}{ 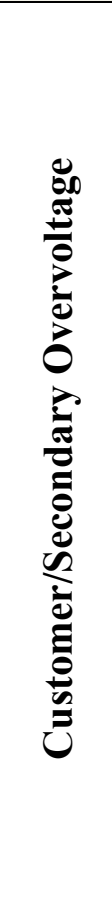 } & EVSE & $\begin{array}{l}\text { - Avoiding charging prior to the time of overvoltage } \\
\text { - Variable control to increase and/or encourage charging at the time of overvoltage } \\
\text { - Monitoring of operational status }\end{array}$ \\
\hline & Thermostat & $\begin{array}{l}\text { Increase HVAC consumption by: } \\
\text { - Temperature offset } \\
\text { - Heightened operation control via duty cycling }\end{array}$ \\
\hline & Pool Pump & Increase consumption by variably increasing the pump speed as needed \\
\hline & $\begin{array}{l}\text { Battery } \\
\text { Storage }\end{array}$ & $\begin{array}{l}\text { - Scheduled operation to store energy during midday } \\
\text { - Configured operation to limit reverse power flow based on measurement } \\
\text { - Dispatched charging (commands sent to the device from a remote entity) } \\
\text { - Monitoring of the battery state of charge }\end{array}$ \\
\hline & $\begin{array}{l}\text { Smart } \\
\text { Inverter }\end{array}$ & $\begin{array}{l}\text { - Fixed maximum operating voltage limits } \\
\text { - Inductive reactive power (acting like an inductive load) during periods of } \\
\text { overvoltage } \\
\text { - Autonomous curtailment of power with increased voltage } \\
\text { - Monitoring voltage }\end{array}$ \\
\hline & Water Heater & $\begin{array}{l}\text { - Avoid heating water ahead of overvoltage periods to accumulate (through normal } \\
\text { water usage) ability to use energy } \\
\text { - Heat water to highest allowed level during periods of overvoltage } \\
\text { - Monitoring of present power level } \\
\text { - Monitoring of the device's thermal condition and associated ability to use energy }\end{array}$ \\
\hline
\end{tabular}




\begin{tabular}{|c|c|c|}
\hline $\begin{array}{c}\text { Grid } \\
\text { Issue }\end{array}$ & Device Type & Summary of Selected Device Actions* \\
\hline \multirow{6}{*}{ 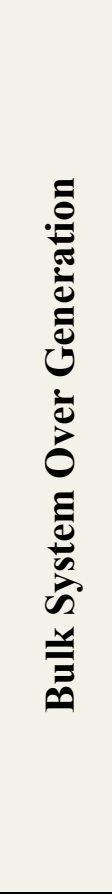 } & EVSE & No actions are recommended for this device $\&$ issue. \\
\hline & Thermostat & No actions are recommended for this device $\&$ issue. \\
\hline & Pool Pump & $\begin{array}{l}\text { - Reduce circulation rate prior to the period of excess generation } \\
\text { - Heighten circulation during the period of excess generation } \\
\text { - Scheduled operation to pump during the known/predictable over-generation period } \\
\text { - Monitoring of the pool pumps remaining ability to use/take energy (e.g. per the } \\
\text { daily schedule) }\end{array}$ \\
\hline & $\begin{array}{l}\text { Battery } \\
\text { Storage }\end{array}$ & $\begin{array}{l}\text { - Dispatched operation to store energy during midday } \\
\text { - Scheduled operation to store energy during known/predictable over-generation } \\
\text { periods } \\
\text { - Monitoring of state-of charge }\end{array}$ \\
\hline & $\begin{array}{c}\text { Smart } \\
\text { Inverter }\end{array}$ & No actions are recommended for this device $\&$ issue \\
\hline & Water Heater & $\begin{array}{l}\text { - Monitoring of present power consumption and present ability to consume energy } \\
\text { - Use duty-cycle control to achieve variable energy use levels (averaged across a } \\
\text { large population of water heaters) during the midday period when solar generation } \\
\text { is high } \\
\text { - Curtailment during the morning period to reserve capability to use energy for } \\
\text { midday } \\
\text { Note: this action could be scheduled in advance }\end{array}$ \\
\hline \multirow{6}{*}{ 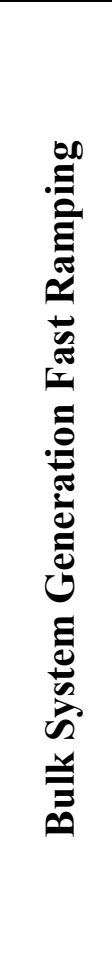 } & EVSE & $\begin{array}{l}\text { - Use dispatched price signals, with increasing price during the 5-8PM period to } \\
\text { encourage reductions in demand as renewable generation is dropping } \\
\text { - Dispatched curtailment signals, sent by system operator as-needed during the 5- } \\
\text { 8PM period } \\
\text { - Use scheduled charging to defer until after 8PM }\end{array}$ \\
\hline & Thermostat & $\begin{array}{l}\text { Ramp-Down HVAC consumption as renewable generation is falling by: } \\
\text { - Temperature Offset } \\
\text { - Scheduled operation to ramp down heating/cooling during the 5-8PM period }\end{array}$ \\
\hline & Pool Pump & $\begin{array}{l}\text { - Scheduled operation to avoid or reduce operation in the 5-8PM period as } \\
\text { renewable generation is dropping } \\
\text { - Dispatched operation to increase consumption (before mid-ramp) and reduce } \\
\text { consumption (following mid-ramp). }\end{array}$ \\
\hline & $\begin{array}{l}\text { Battery } \\
\text { Storage }\end{array}$ & $\begin{array}{l}\text { - Monitoring of present state of charge } \\
\text { - Scheduled operation to ramp down energy storage and ramp up energy } \\
\text { discharging during the 5-8PM period. } \\
\text { - Dispatched operation to ramp down energy storage and ramp up energy } \\
\text { discharging during the 5-8PM period. }\end{array}$ \\
\hline & $\begin{array}{c}\text { Smart } \\
\text { Inverter }\end{array}$ & No actions are recommended for this device $\&$ issue. \\
\hline & Water Heater & $\begin{array}{l}\text { - Dispatched operation to increase consumption prior to the time period of concern } \\
\text { then transition to reduced consumption during the period of concern. } \\
\text { Note: This action could be potentially scheduled in advance via communication } \\
\text { system and/or modules }\end{array}$ \\
\hline
\end{tabular}




\begin{tabular}{|c|c|c|}
\hline $\begin{array}{l}\text { Grid } \\
\text { Issue }\end{array}$ & Device Type & Summary of Selected Device Actions* \\
\hline \multirow{6}{*}{ 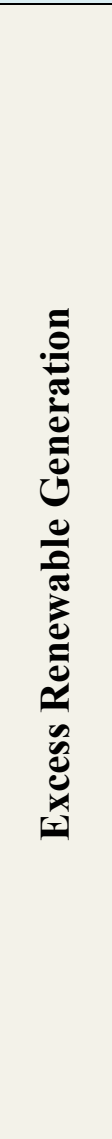 } & EVSE & $\begin{array}{l}\text { - Vehicles reserving a percentage of energy storage take capability } \\
\text { - EVSE learning patterns of charging to improve estimation of availability } \\
\text { - Dispatched curtailment/avoidance of charging prior to periods of excess renewable } \\
\text { generation } \\
\text { - Dispatched operation during periods of excess renewable generation }\end{array}$ \\
\hline & Thermostat & $\begin{array}{l}\text { - Dispatched Temperature offset control to increase load. } \\
\text { - Dispatched duty-cycle control to achieve controllable increases in load that can be } \\
\text { maintained over a longer period of time } \\
\text { - Note: Fixed scheduling not deemed useful due to non-predictability of events. }\end{array}$ \\
\hline & Pool Pump & $\begin{array}{l}\text { - Monitoring of present real power level. } \\
\text { - Monitoring of present ability to use energy based on the scheduled daily } \\
\text { circulation plan } \\
\text { Dispatched increase in energy consumption to heighten circulation during periods } \\
\text { of excess renewables } \\
\text { Note: Fixed scheduling not deemed useful due to non-predictability of events. }\end{array}$ \\
\hline & $\begin{array}{l}\text { Battery } \\
\text { Storage }\end{array}$ & $\begin{array}{l}\text { - Dispatched limitation on level of generation } \\
\text { - Dispatched charge command } \\
\text { - Autonomous power curtailment if/when frequency becomes high } \\
\text { - Autonomous power curtailment if/when voltage becomes high }\end{array}$ \\
\hline & $\begin{array}{c}\text { Smart } \\
\text { Inverter }\end{array}$ & $\begin{array}{l}\text { - Monitoring of the present real power level } \\
\text { - Dispatched limitation of maximum generated power } \\
\text { - Autonomous reduction in generation if/when frequency becomes high. }\end{array}$ \\
\hline & Water Heater & $\begin{array}{l}\text { - Monitoring of present power level } \\
\text { - Monitoring of the device's thermal condition and associated ability to use energy } \\
\text { - Dispatched increase in energy consumption (e.g. holding tighter to the maximum } \\
\text { temperature setpoint or shifting to a higher setpoint) to heighten water heating } \\
\text { during periods of excess renewables. }\end{array}$ \\
\hline
\end{tabular}

* Note: The selected device actions are not the only actions possible, but are those identified by the project team and technical advisory group as being best suited based on the assumptions of the "grid issue". 


\section{Product Implementation}

Following the identification of desired functionality for each product type, the manufacturers set out individually to implement support in their products. In the course of doing this, each manufacturer developed specific detailed ways of providing action, seeking to optimize the service provided to the grid while maintaining consumer comfort to the extent possible. Although the resulting product behaviors are evident in the laboratory test results, the internal algorithms and techniques employed were the invention of the individual manufacturers and were not documented or made public. For example, the water heater manufacturer developed a means to estimate the present state of stored thermal energy in the tank. Table 4-1 provides summary descriptions of the capabilities implemented, including features like consumer override and boundaries imposed on responses to limit impact on consumer comfort.

According to the project plan, this step was determined to utilize open standards to the extent possible, and if gaps were found, to identify extensions to improving their applicability to the use cases at hand. This resulted in a mapping exercise in which best-fit messages from the selected protocol standards were identified to support each device function. These selections are identified in the right-hand column of Table 4-1.

Reorganizing the requirements identified in Table 3-1, Table 4-1 consolidates on a per-device basis the key actions that resulted from the high-penetration solar grid issues. It was noted by the project team that these action lists are short in comparison to the range of grid issues, or reasons that each may be requested. In other words, the message sent to the end device only needs to identify the action requested, not the grid issue that motivated the request. The communication standards involved in the project appeared to be designed accordingly, with defined messages that relate only to the action being requested and not attempting to communicate the reason (e.g. specific grid issue) behind the request.

Table 4-4. Summary of Communication Standards Utilization and Support for Required Functionality

\begin{tabular}{|c|c|c|}
\hline Device & $\begin{array}{c}\text { Designed Device Actions } \\
\text { (Based on the Requirements Identified } \\
\text { in Table 3-1) }\end{array}$ & $\begin{array}{c}\text { Standard Protocol and Message Usage to } \\
\text { Support }\end{array}$ \\
\hline \multirow{8}{*}{$\stackrel{\text { Ш }}{\text { Ш }}$} & Scheduled operation & $\begin{array}{l}\text { N/A, communication not involved for scheduled } \\
\text { operation }\end{array}$ \\
\hline & Increase the EV charging rate. & CTA-2045 “Load-Up" command \\
\hline & Mildly decease the EV charging level & CTA-2045 "Shed" command \\
\hline & $\begin{array}{l}\text { Aggressively decrease the EV charging } \\
\text { level }\end{array}$ & CTA-2045 “Critical Event" command \\
\hline & Halt EV charging & CTA-2045 “Grid Emergency" command \\
\hline & Adjust the EV charging level variably & CTA-2045 "Request for Power Level" command \\
\hline & Monitoring of the EVSE status of operation & Use the CTA-2045 "Operating Status" query \\
\hline & Monitoring real power level & $\begin{array}{l}\text { CTA-2045 "Commodity Read", Instantaneous } \\
\text { Electricity Consumed }\end{array}$ \\
\hline
\end{tabular}




\begin{tabular}{|c|c|c|}
\hline Device & $\begin{array}{c}\text { Designed Device Actions } \\
\text { (Based on the Requirements Identified } \\
\text { in Table 3-1) }\end{array}$ & $\begin{array}{c}\text { Standard Protocol and Message Usage to } \\
\text { Support }\end{array}$ \\
\hline & $\begin{array}{l}\text { Stop charging to reserve a certain (small) } \\
\text { percentage of storage capacity }\end{array}$ & $\begin{array}{l}\text { Not implemented, the EVSE cannot } \\
\text { communicate with the EV to determine the state } \\
\text { of charge }\end{array}$ \\
\hline & $\begin{array}{l}\text { Estimate the availability to charge/store } \\
\text { energy based on historical data }\end{array}$ & $\begin{array}{l}\text { Not implemented during the project timeframe. } \\
\text { Not effectively supported in CTA-2045. }\end{array}$ \\
\hline \multirow{6}{*}{$\begin{array}{l}\frac{\hbar \pi}{\frac{\pi}{0}} \\
\stackrel{0}{0} \\
\stackrel{5}{\Phi} \\
\stackrel{5}{F}\end{array}$} & $\begin{array}{l}\text { Reduce HVAC consumption using a fixed } \\
\text { setpoint offset }\end{array}$ & $\begin{array}{l}\text { CTA-2045 "Shed" command, with specified event } \\
\text { duration }\end{array}$ \\
\hline & $\begin{array}{l}\text { Increase HVAC consumption using a fixed } \\
\text { setpoint offset }\end{array}$ & $\begin{array}{l}\text { CTA-2045 "Load-Up" command with specified } \\
\text { event duration }\end{array}$ \\
\hline & $\begin{array}{l}\text { Increase HVAC consumption by a } \\
\text { specified temperature offset }\end{array}$ & CTA-2045 "Set Temperature Offset" command \\
\hline & $\begin{array}{l}\text { Increase HVAC consumption by } \\
\text { heightened operation control via duty } \\
\text { cycling }\end{array}$ & $\begin{array}{l}\text { CTA-2045 "Start Cycling" and "Terminate } \\
\text { Cycling" commands }\end{array}$ \\
\hline & $\begin{array}{l}\text { Support scheduled operation based on } \\
\text { time-of-day }\end{array}$ & $\begin{array}{l}\text { Supported by the manufacturer locally on the } \\
\text { device. Communication not involved. }\end{array}$ \\
\hline & $\begin{array}{l}\text { Monitor HVAC system state and/or } \\
\text { estimated power consumption }\end{array}$ & $\begin{array}{l}\text { CTA-2045 "Operating Status" query for system } \\
\text { state } \\
\text { CTA-2045 "Commodity Read", Instantaneous } \\
\text { Electricity Consumed }\end{array}$ \\
\hline \multirow{6}{*}{ 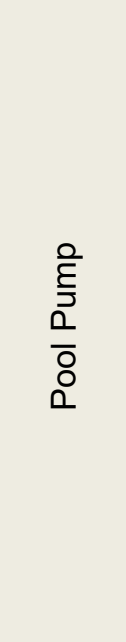 } & $\begin{array}{l}\text { Locally-scheduled operation to control } \\
\text { time-of-use }\end{array}$ & $\begin{array}{l}\mathrm{N} / \mathrm{A} \text {, communication not involved for scheduled } \\
\text { operation }\end{array}$ \\
\hline & $\begin{array}{l}\text { Dispatched decrease of power } \\
\text { consumption by reducing pump circulation } \\
\text { rate }\end{array}$ & CTA-2045 "Shed" command \\
\hline & $\begin{array}{l}\text { Dispatched increase of power consumption } \\
\text { by increasing pump circulation rate }\end{array}$ & CTA-2045 “Load-Up” command \\
\hline & $\begin{array}{l}\text { Variably increase and decrease the power } \\
\text { consumption of the pool pump }\end{array}$ & CTA-2045 "Request for Power Level" command \\
\hline & Monitoring of present real power level & $\begin{array}{l}\text { CTA-2045 “Commodity Read", Instantaneous } \\
\text { Electricity Consumed }\end{array}$ \\
\hline & $\begin{array}{l}\text { Monitoring of the remaining daily amount } \\
\text { of energy the pool pump system can utilize }\end{array}$ & $\begin{array}{l}\text { CTA-2045 “Commodity Read", Present Energy } \\
\text { Storage Capacity }\end{array}$ \\
\hline
\end{tabular}




\begin{tabular}{|c|c|c|}
\hline \multirow{10}{*}{ 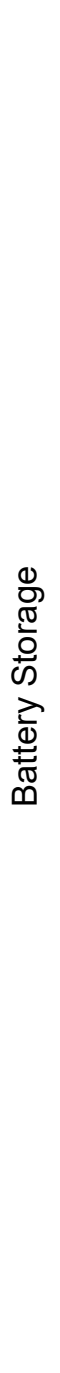 } & $\begin{array}{l}\text { Self-managed active power as a function of } \\
\text { local voltage }\end{array}$ & $\begin{array}{l}\text { IEC61850-7-420 Volt-Watt function, DNP3 } \\
\text { AN-001 } 2013 \text { protocol, Analog Output points } \\
772-827\end{array}$ \\
\hline & $\begin{array}{l}\text { Self-managed active power as a function of } \\
\text { frequency }\end{array}$ & $\begin{array}{l}\text { IEC61850-7-420 Frequency-Watt function, } \\
\text { DNP3 AN-001 } 2013 \text { protocol, AO points } 772- \\
827\end{array}$ \\
\hline & $\begin{array}{l}\text { Self-managed reactive power as a function of } \\
\text { local voltage }\end{array}$ & $\begin{array}{l}\text { IEC61850-7-420 Volt-Var function, DNP3 AN- } \\
0012013 \text { protocol, AO points } 772-827\end{array}$ \\
\hline & Adjustable power factor & $\begin{array}{l}\text { IEC61850-7-420 Fixed PF Function, DRCT, } \\
\text { Out PFSet, DNP3 AN-001 } 2013 \text { protocol, AO } \\
\text { point } 17\end{array}$ \\
\hline & $\begin{array}{l}\text { Scheduled operation to charge/discharge } \\
\text { according to a time-of-day schedule }\end{array}$ & $\begin{array}{l}\text { IEC61850-7-420 scheduled } \\
\text { "Charge/Discharge Function", DNP3 AN-001 } \\
2013 \text { protocol }\end{array}$ \\
\hline & $\begin{array}{l}\text { Dispatched operation to charge at a specified } \\
\text { rate }\end{array}$ & $\begin{array}{l}\text { IEC61850-7-420 dispatched } \\
\text { "Charge/Discharge Function", DNP3 AN-001 } \\
2013 \text { protocol }\end{array}$ \\
\hline & $\begin{array}{l}\text { Dispatched operation to discharge at a } \\
\text { specified rate }\end{array}$ & $\begin{array}{l}\text { IEC61850-7-420 dispatched } \\
\text { "Charge/Discharge Function", DNP3 AN-001 } \\
2013 \text { protocol }\end{array}$ \\
\hline & $\begin{array}{l}\text { Autonomous function to limit maximum } \\
\text { reverse power flow }\end{array}$ & $\begin{array}{l}\text { IEC61850-7-420 “Max Generation Limit" } \\
\text { function, DRCT, WMaxLimPct, DNP3 AN-001 } \\
2013 \text { protocol, Analog Output point } 15\end{array}$ \\
\hline & Monitoring of present real power level & $\begin{array}{l}\text { IEC61850-7-420 Status Monitoring, MMXU, } \\
\text { TotW, DNP3 AN-001 } 2013 \text { protocol, AI point } \\
8, \text { Inverter active power output }\end{array}$ \\
\hline & Monitoring of present state of charge & $\begin{array}{l}\text { IEC61850-7-420 Status Monitoring, ZBAT, } \\
\text { AhrPct, DNP3 AN-001 } 2013 \text { protocol, Al point } \\
25 \text { - State of Charge }\end{array}$ \\
\hline \multirow{6}{*}{ 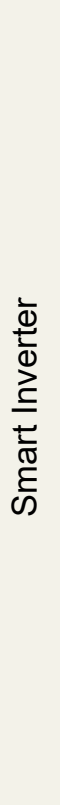 } & $\begin{array}{l}\text { Limit maximum solar generation to a } \\
\text { percentage of plant capacity }\end{array}$ & $\begin{array}{l}\text { IEC61850-7-420 Max Generation Limit } \\
\text { Function, DRCT, WMaxLimPct, SunSpec } \\
\text { Modbus protocol }\end{array}$ \\
\hline & Remotely-adjustable power factor & $\begin{array}{l}\text { IEC61850-7-420 Fixed Power Factor } \\
\text { Function, DRCT, OutPFSet, SunSpec } \\
\text { Modbus protocol }\end{array}$ \\
\hline & $\begin{array}{l}\text { Configurable, self-managed reactive power } \\
\text { based on voltage at the inverter point of } \\
\text { connection }\end{array}$ & $\begin{array}{l}\text { IEC61850-7-420 Volt-Var function, SunSpec } \\
\text { Modbus protocol }\end{array}$ \\
\hline & $\begin{array}{l}\text { Configurable, self-managed active power } \\
\text { output vs voltage at the inverter point of } \\
\text { connection }\end{array}$ & $\begin{array}{l}\text { IEC61850-7-420 Volt-Watt function, SunSpec } \\
\text { Modbus protocol }\end{array}$ \\
\hline & $\begin{array}{l}\text { Configurable, self-managed active power } \\
\text { based on frequency at the inverter point of } \\
\text { connection }\end{array}$ & $\begin{array}{l}\text { IEC61850-7-420 standard Frequency-Watt } \\
\text { function, using the SunSpec Modbus protocol }\end{array}$ \\
\hline & Fixed maximum operating voltage limits & $\begin{array}{l}\text { N/A Not adjustable via communication } \\
\text { interface }\end{array}$ \\
\hline
\end{tabular}




\begin{tabular}{|c|c|c|}
\hline & $\begin{array}{l}\text { Monitoring of } \mathrm{AC} \text { voltage at the point of } \\
\text { connection }\end{array}$ & $\begin{array}{l}\text { IEC61850-7-420 Status Monitoring, MMXU, } \\
\text { PhV.PhsA.mag, SunSpec Modbus protocol }\end{array}$ \\
\hline & Monitoring of present real power level & $\begin{array}{l}\text { IEC61850-7-420 standard Status Monitoring, } \\
\text { Real Power Delivered, using the SunSpec } \\
\text { protocol }\end{array}$ \\
\hline \multirow{6}{*}{$\begin{array}{l}\frac{1}{\Phi} \\
\stackrel{ \pm}{\mathbb{N}} \\
\stackrel{\Phi}{1} \\
\bar{\Phi} \\
\stackrel{\mathbb{N}}{3} \\
3\end{array}$} & Moderate reduction of target stored hot water & CTA-2045 "Shed" command \\
\hline & $\begin{array}{l}\text { Aggressive reduction of target stored hot } \\
\text { water }\end{array}$ & CTA-2045 "Critical Peak" command \\
\hline & $\begin{array}{l}\text { Ability to top-off, to increase the stored hot } \\
\text { water target }\end{array}$ & CTA-2045 “Load-Up" command \\
\hline & $\begin{array}{l}\text { Ability to operate at a specified duty-cycle to } \\
\text { achieve variable levels of water heating per } \\
\text { hour }\end{array}$ & $\begin{array}{l}\text { CTA-2045 "Start Cycling" and "Terminate } \\
\text { Cycling" commands }\end{array}$ \\
\hline & Monitoring of present real power level & $\begin{array}{l}\text { CTA-2045 “Commodity Read", Instantaneous } \\
\text { Electricity Consumed }\end{array}$ \\
\hline & $\begin{array}{l}\text { Monitoring of the present level of energy that } \\
\text { can be absorbed/used by the water heater }\end{array}$ & $\begin{array}{l}\text { CTA-2045 "Commodity Read", Present } \\
\text { Energy Storage Capacity }\end{array}$ \\
\hline
\end{tabular}




\section{Laboratory Testing and Result Highlights}

Individual test plans were developed and published separately for each device type. These plans established the requirements for the laboratory and guided the testing processes. All final testing was performed in the NREL ESIF System Performance Laboratory (SPL).

\subsection{Communication Test Tools}

The communication interfaces of each product were open standards and locally available at the device as identified in Table 5-1.

Table 5-5, Device Open Standard Communication Interfaces

\begin{tabular}{|l|l|}
\hline \multicolumn{1}{|c|}{ Product } & \multicolumn{1}{c|}{ Communication Interface } \\
\hline Siemens EVSE & CTA-2045, DC form factor \\
\hline Emerson Thermostat & CTA-2045, DC form factor \\
\hline Pentair Pool Pump & CTA-2045, AC form factor \\
\hline AO Smith Resistive Water Heater & CTA-2045, AC form factor \\
\hline AO Smith Heat Pump Water Heater & CTA-2045, AC form factor \\
\hline Fronius Solar Inverter & SunSpec Modbus, AC form factor \\
\hline PowerHub Battery Energy Storage & $\begin{array}{l}\text { DNP3 AN 2013-001, SunSpec } \\
\text { Modbus/TCP }\end{array}$ \\
\hline
\end{tabular}

The project team provided the PC-based tools and communication cables identified in Table 5-2 that enabled testing in the SPL by plugging directly into the products. In actual field scenarios, various communication modules and modems would be connected into the same ports to integrate the products into the systems. 
Table 5-6. Test Tools Summary

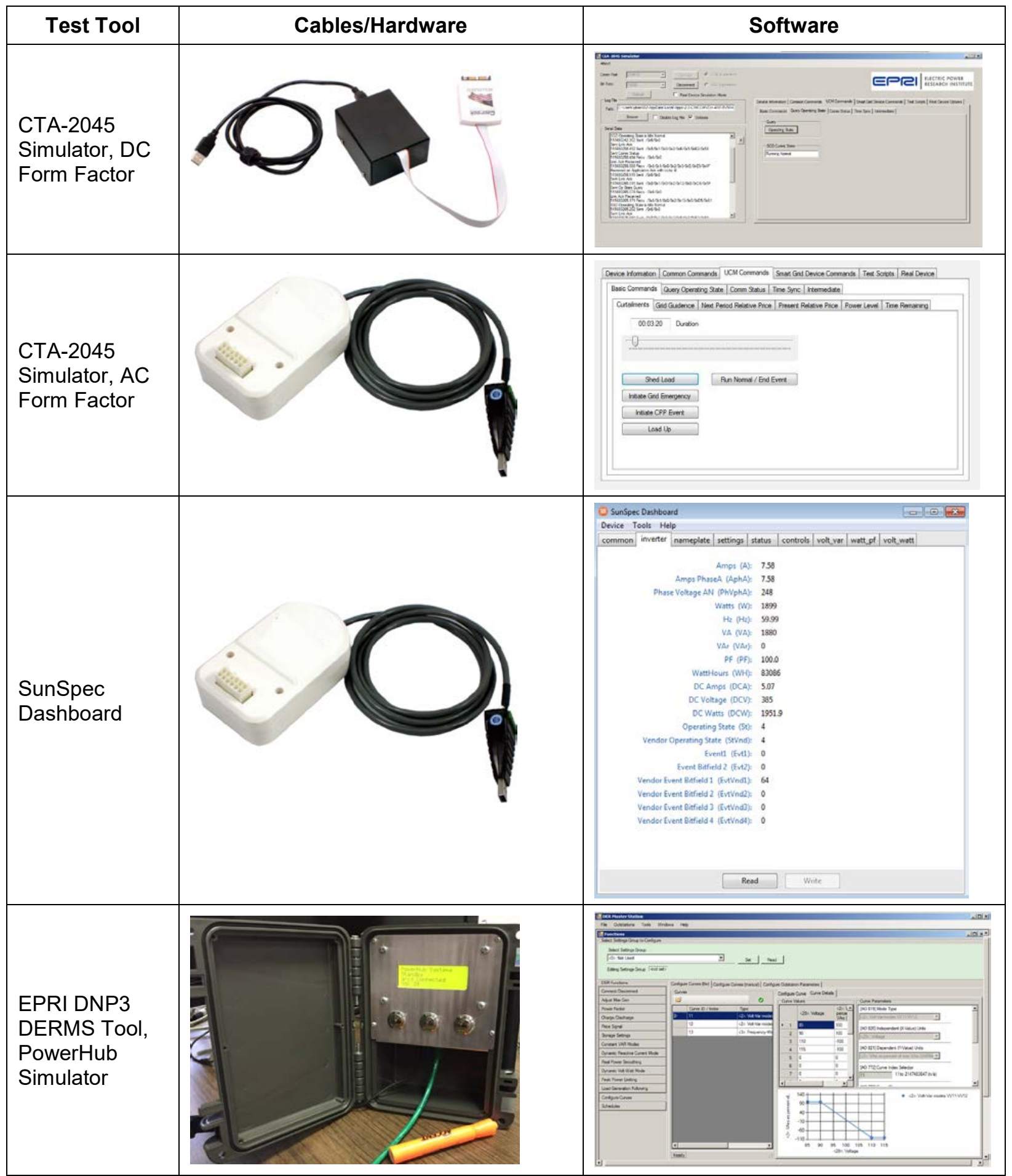

\subsection{Testing and Test Results}

Individual test result documents were produced for each device type and were published separately. The following sections provides highlights of the testing for each device. 


\subsubsection{Siemens EVSE Testing}

The EVSE was able to achieve quantified variable levels of control by way of manipulating the duty-cycle of the pilot wire in the charging cable (SAE J1772) as indicated in Figure 5-1.

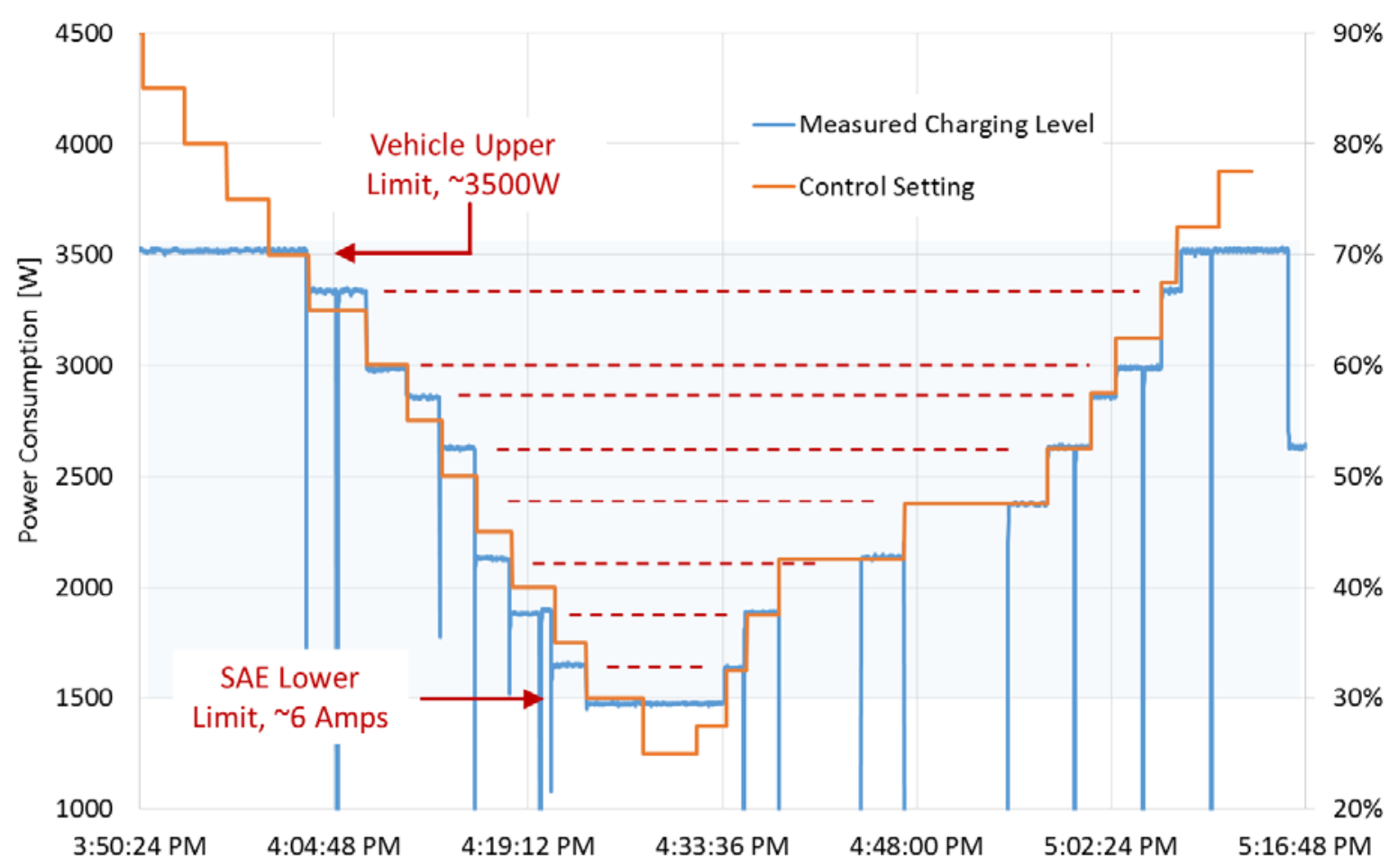

Figure 5-3. EVSE Variable Control Test Results

It is noted that the intended use for the PWM signal between the EVSE and the vehicle is to set a maximum charging limit so that the vehicle does not draw more current than the circuit can handle. It is therefore allowed for the vehicle to draw less current than what is requested. For the vehicle tested (a Scion iQev), two characteristics are particularly visible in this test data:

1. The vehicle pauses charging for a few seconds once every few minutes, perhaps as part of the battery state-of-charge assessment

2. While the EVSE accepted and acted upon any power-level request to $1 \%$ resolution, the actual charge levels performed by the vehicle appear to have been quantified to a limited number of steps, the details of which are not known.

While these characteristics may not matter for certain use cases, such as those that involve that aggregate effect of many charging vehicles, it is noted that they may disrupt other use cases such as local generation following. Improved results may be possible in future scenarios with twoway communication between the EVSE and the vehicle and an intentional variable dispatch function, but such capability was not supported at the time of this testing. With two-way communication, the EVSE could know the state-of charge of the vehicle, and possibly the time at which the vehicle is needed could be read. An intentional variable dispatch function would be superior to the present approach in that it would request that the vehicle actually hold-to a given charge level rather than just staying below a defined ceiling. 
The EVSE also supported a number of curtailment and status monitoring functions as identified in the full test report.

\subsubsection{AO Smith Water Heater Testing}

The project tested both resistive and heat-pump water heaters. Each product provided a range of response types which resulted in changes in the water heater's target level of heated water (stored energy) in the tank.

The water heaters had separate top and bottom heating capability and temperature sensors. The manufacturer used these to improve customer comfort, maintaining the outlet water temp to the extent possible during control periods. Water temperature in a tank type heater tends to be stratified, with colder water at the bottom of the tank near the inlet and hot water at the top of the tank near the outlet. The manufacturer's control algorithms took advantage of this characteristic to provide demand responses while maintaining at or near normal outlet water temperature.

In order to support the various demand-response actions, the manufacturer developed a method of estimating the present level of stored thermal energy in the tank. From this, the present ability to use or take energy was calculated and provided as a monitorable parameter through the communication interface. This parameter, referred to as "Energy Take" proved to be very useful in understanding the present state of the water heater and predicting the resource availability.

The normal mode of operation for water heaters is to fully heat the water in the tank, resulting in little or no ability to absorb energy if/when needed to support high levels of renewable energy. For this reason, a combination of control commands were envisioned, with curtailments being called in advance of periods of excess renewable energy in order to create capacity to dispatch energy into the water heaters at a later time.

Figure 5-2 provides results from a representative test of the resistive water heater. The black trace is water draw [gallons-per-minute], the orange trace power consumption [Watts], and the blue trace the "Energy Take" parameter [Watt-hours] read from the device. At the left side of the chart, the water heater is in a normal mode of operation. When water draw occurs, the Energy-Take parameter rises. When Energy-Take reaches around 700[Wh], the water heater turns on and operates until the tank is fully reheated and the Energy-Take capability is zero.

At 3:10PM, a curtailment event is called and another water draw takes place. In this case, the water heater doesn't turn on until the tank has much less stored thermal energy and the EnergyTake capability reading is $\sim 2300[\mathrm{Wh}]$. When it does turn on, as seen at 3:57PM, it only operates for a few minutes, maintaining a high Energy-Take capability. 


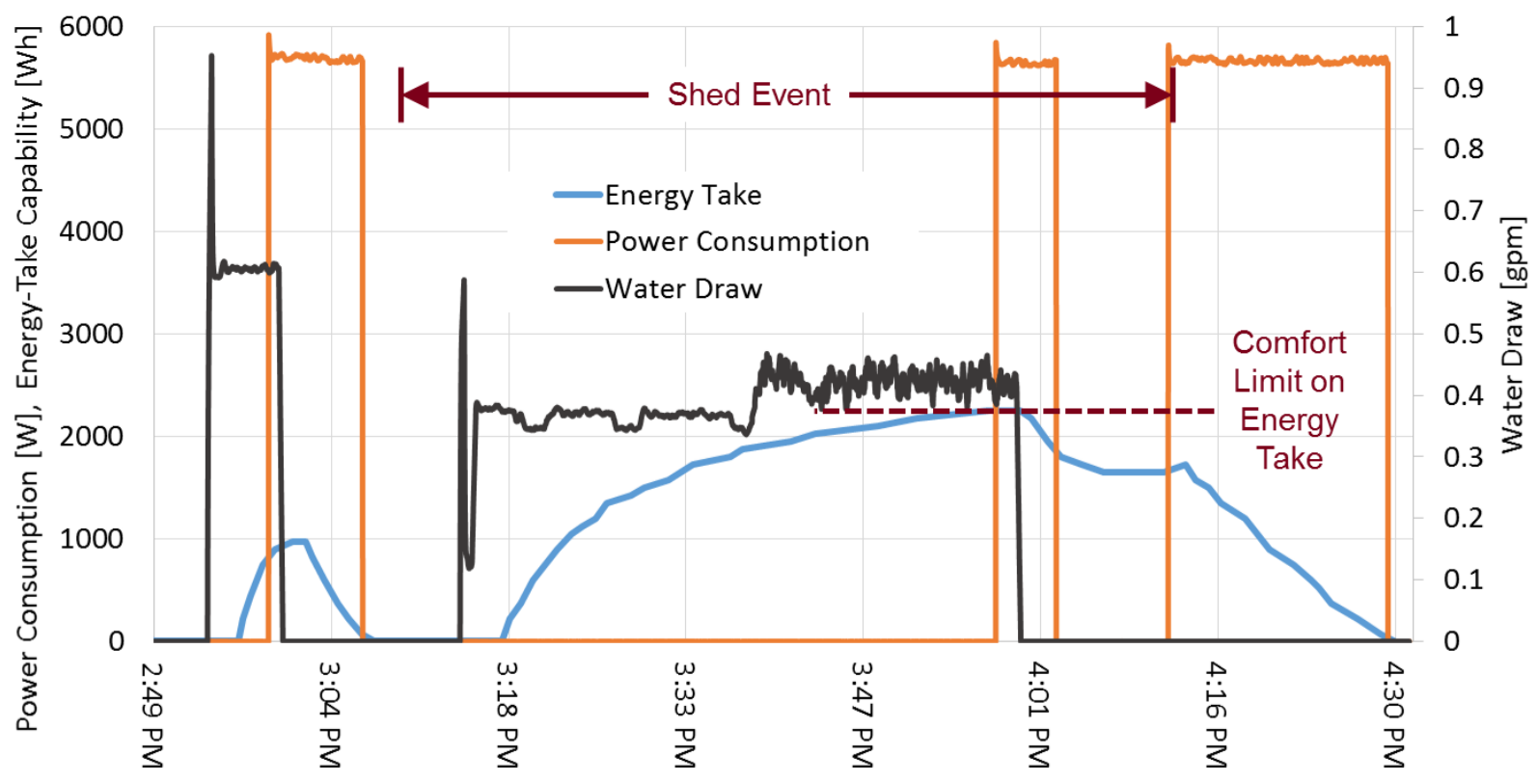

Figure 5-4. Resistive Water Heater Curtailment Function Test Results

Figure 5-3 provides results from a test of the heat pump water heater, with the traces and colors the same as in Figure 5-2. This product was more complex in that it could heat using resistive elements, a heat pump, or both. During this test, a curtailment event was initiated at 7:06PM, immediately followed by water draw. Similar to the resistive water heater, the unit did not operate until the Energy-Take capability reached around 2300[Wh]. At that point, it turned on both the resistive $(\sim 4500 \mathrm{~W})$ and heat pump $(\sim 500 \mathrm{~W})$ for a total of $\sim 5000$ [Watts] of power consumption.

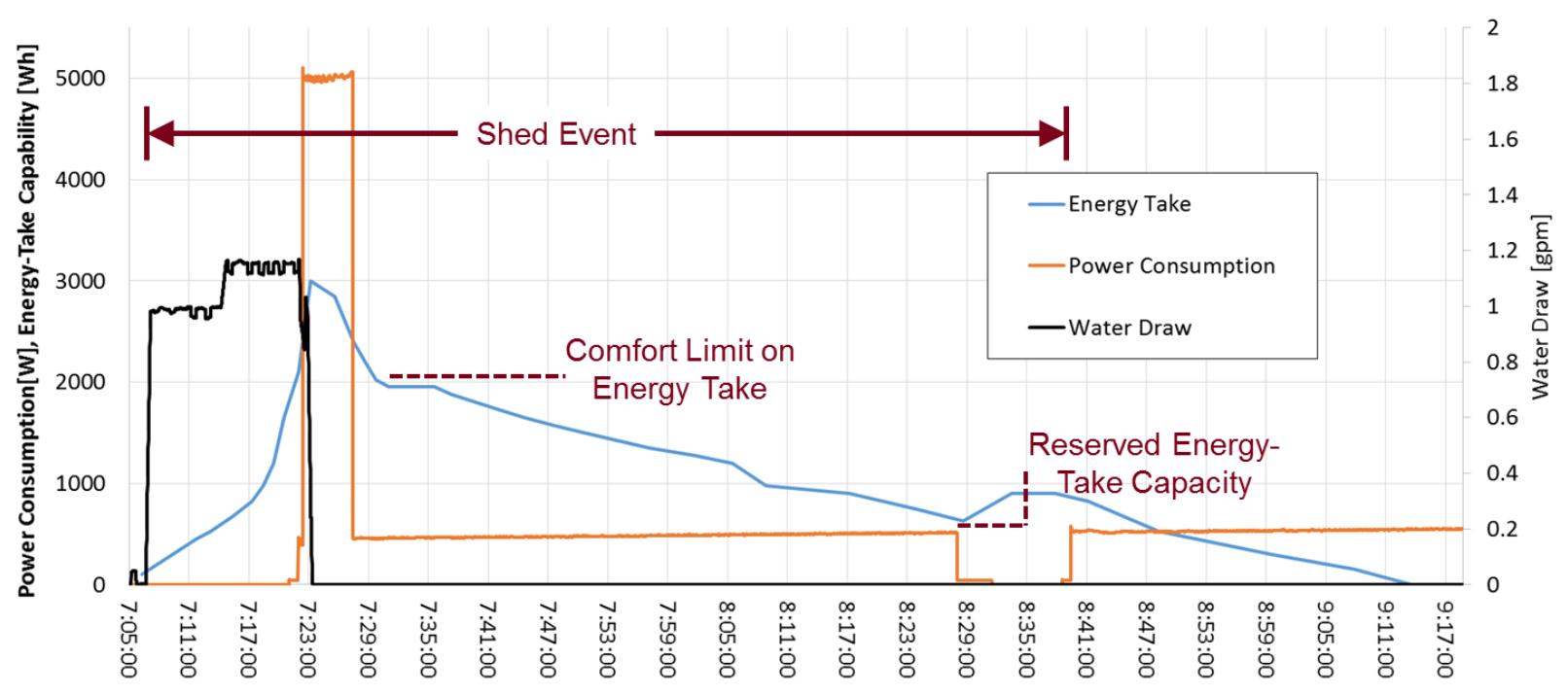

Figure 5-5. Heat-Pump Water Heater Curtailment Function Test Results

Both heating sources continued operation for $\sim 5$ minutes, doing all possible to prevent further reduction in the level of stored thermal energy. When the Energy-Take parameter reversed direction and began to fall, the resistive element turned off and the water heater power 
consumption dropped to $\sim 500[\mathrm{~W}]$. The heat pump then continued to operate until the EnergyTake level was $\sim 600[\mathrm{Wh}]$. In the context of this project, this low-power recovery was considered an area to be improved in the algorithm because the goal of the curtailment command was specifically intended to build and maintain capacity to accept energy at a later time. The full water heater test plans and results have been documented separately.

\subsubsection{Emerson Thermostat Testing}

The thermostat provided a range of response types, typically based on temperature offsets higher or lower. In this way, the behavior of the thermostat was sensitive to consumer needs, curtailing or adding energy consumption only so much, then operating as required to maintain comfort. Temperature offsets resulted in a temporary "control point" or "control temperature" that returned to the customers "setpoint" once the event expired or was terminated.

This characteristic can be seen in the test result example of Figure 5-4. The In response to the curtailment command, the thermostat shifted the control temperature by $4\left[{ }^{\circ} \mathrm{F}\right]$ (blue trace shows the impact of that shift). As indicated to the right of the figure, the HVAC system would still operate (orange trace), during the curtailment event, but only enough to maintain temperature around the offset temperature target. For safety, the thermostat imposes a maximum control temperature of $80\left[{ }^{\circ} \mathrm{F}\right]$ which it will not exceed in any event.

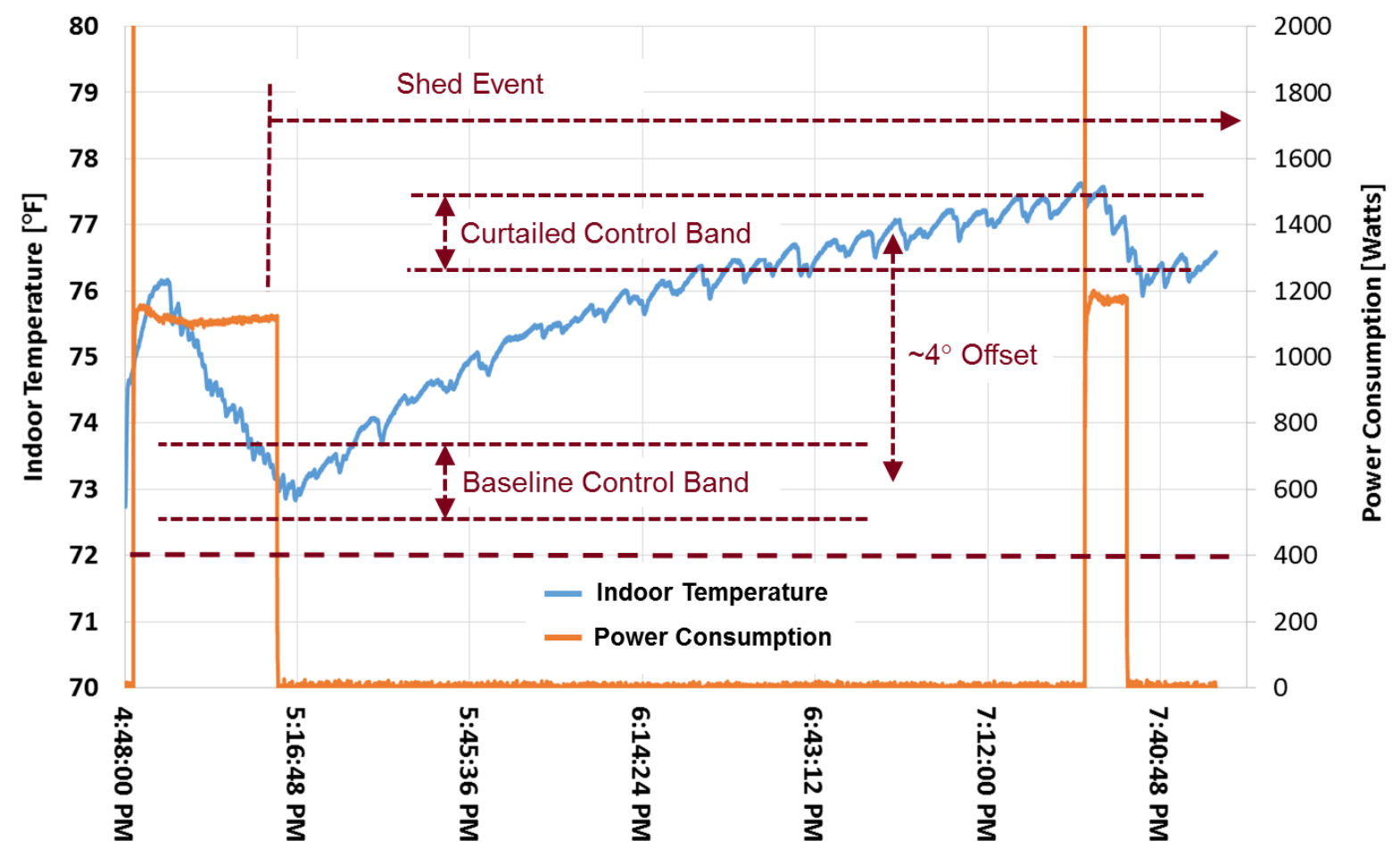

Figure 5-6. Thermostat Curtailment Function Test Results

*Notes regarding Figure 5-4:

1. The temperature rise and fall at the left edge of the diagram are the result of the test system and chamber turn-on and simulation start-up.

2. As can be seen at the operational transition points, the NREL thermal simulation system appropriately modeled the lag time in which the thermostat temperature continues to rise for a brief time following turnon and continues to fall for a brief time following turn-off. 
A notable feature of the thermostat was the consumer interface, including both control buttons and display items as indicated in Figure 5-5. While all the products in this project provided some means for indicating events and initiating event-overrides, the thermostat display supported text and was used to provide event times, durations, and types so that the consumer could be well informed of the present and upcoming conditions.

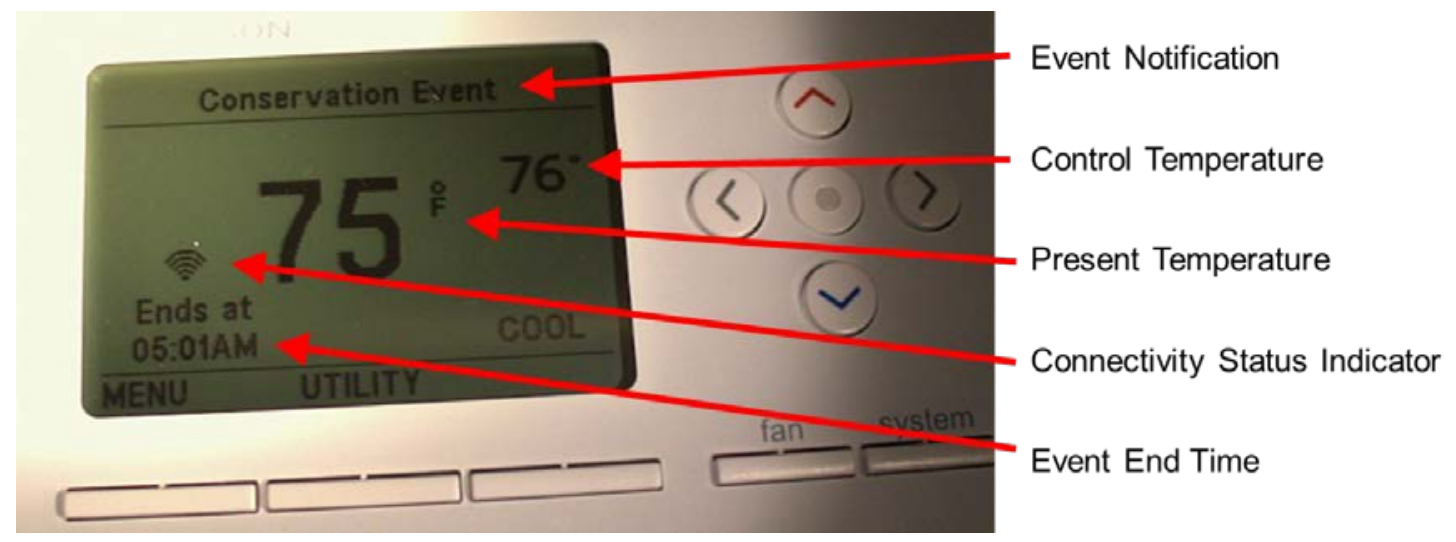

Figure 5-7. Thermostat User Interface

\subsubsection{Pentair Pool Pump Testing}

The pool pump involved in this evaluation was a high efficiency variable speed device. This made it particularly flexible and able to support functions involving both increased (load up) and decreased (shed) energy use. The pool pump supported functions such as shed, critical peak, and load-up with self-managed responses, as well as the variable power function with continuously adjustable output.

A unique feature of the pool pump was its ability to intelligently manage its operation so that its daily circulation requirements are met (an important safety feature), and not exceeded, in the presence of various demand response events. Specifically, the controller kept track of its activity so that:

- If requested to run earlier than scheduled, it would do so, but would finish earlier in the day so as not to perform unnecessary circulation

- If requested to curtail operation or delay, it would do so, but would run when it became necessary to ensure that it could complete its daily circulation

- If requested to run at a higher power level, it would speed up accordingly, but would complete its daily work earlier as a result

- If requested to run at a lower power level, it would slow accordingly, but would run longer in the day as needed to finish its daily circulation

The benefit of this type of smart response, in contrast to a conventional load-control switch, is that the utility or other entity managing the DR program can make full and aggressive use of the load resource without concern that their actions will result in unsafe or unsatisfactory behavior of the end device. The end result is then a significantly greater value and utilization of the load resource because they do not have err on the side of caution.

Examples of this type of smart response and recovery are shown in Figure 5-6 and Figure 5-7: 


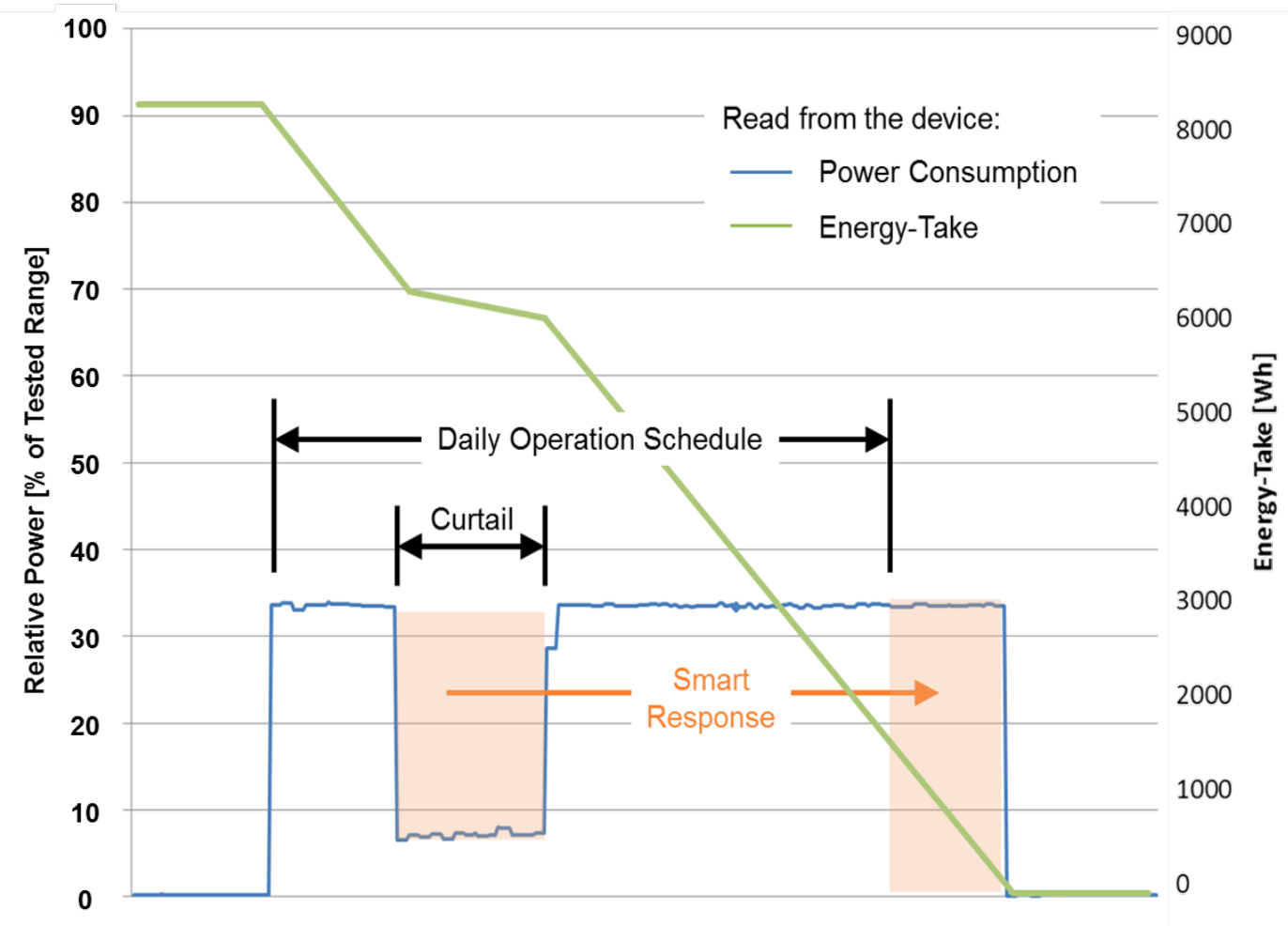

Figure 5-8. Pool Pump Smart Shed Response Test Results

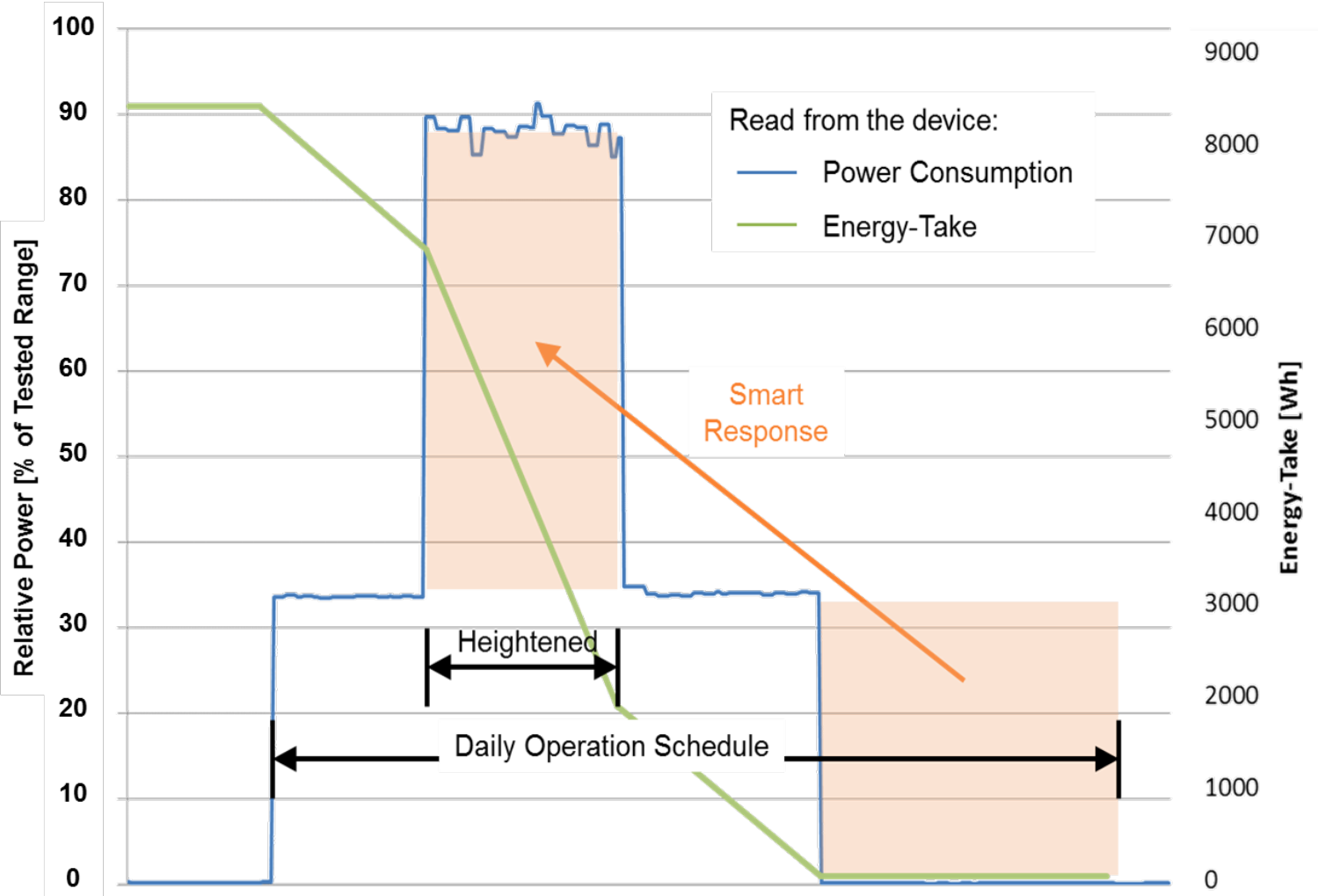

Figure 5-9. Pool Pump Smart Load-Up Response 
During testing of the pool pump's variable speed capabilities, it was noted that the ability to increase consumption (speeding up) is particularly useful in relation to enabling the integration of renewables. The normal behavior of the pump controller is to optimize efficiency, which results in operation at a lower speed for longer periods of time, with normal power consumption of only a few hundred watts. But as indicated in the variable test results of Figure 5-8, the unit can be variably adjusted upward. According to the manufacturer, this model can operate at levels up to 3000 [W]. This is comparable to the scale of a typical residential solar installation and makes the pool pump a substantial resource for productive use of excess renewable energy.

The uneven step sizes in Figure 5-8 result from Pentair's implementation, which directly varied the pump speed, rather than its power, in response to the variable power request function. This implementation, which was not proper relative to the CTA-2045 standard which specifies that the value sent is to be a linear \% power, is subsequently being adjusted. The relationship between the pump speed and its power is a cubic function, hence the uneven step sizes.

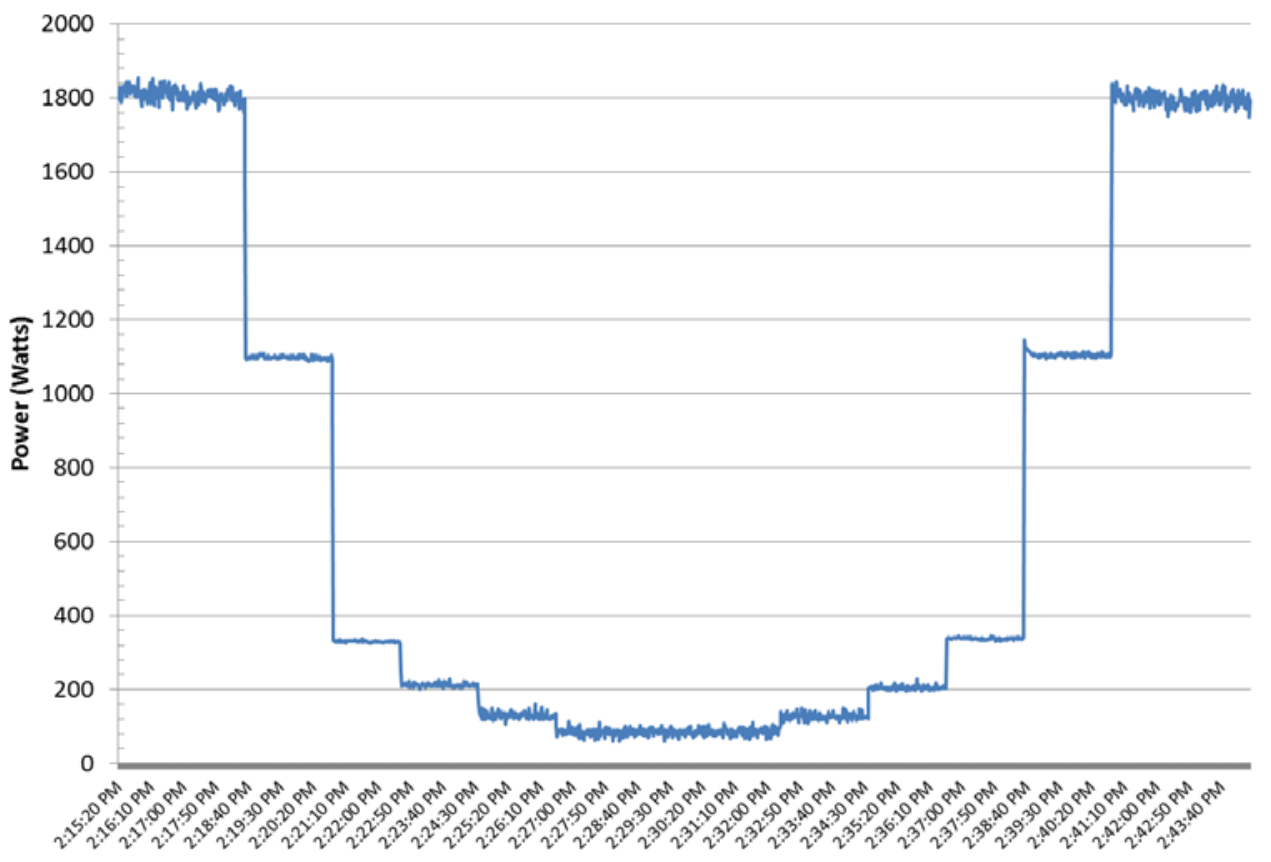

Figure 5-10. Pool Pump Variable Speed Control Test Results

In the arrangement tested, there was a time-delay of several seconds in the firmware of the Pentair demand response controller (a delay from message-received to control-out to the pump), however the pump then responded quickly ( $<1$ second) to controls. Pentair noted that the timedelay could be eliminated from the controller, and the core ability of the pool pump to ramp up and down rapidly could then be used to help mitigate the variability of solar generation.

\subsubsection{Fronius Smart Inverter Testing}

In view of the goal of enabling more renewable energy on the grid, the project team identified functional requirements for the solar inverter from a different perspective. Instead of simply asking "what can this device do to help mitigate the issue", the team asked "what can be done to 
enable this device to produce maximum energy". While curtailment of real power production from the solar inverter was identified as a requirement, it was viewed as a last resort.

The solar inverter provided a range of grid-supportive functions as identified in Table 5-3 and detailed separately in the full test plan and results. A key feature that sets the solar inverter apart from the load devices represented in the project is its ability to produce and absorb reactive power. This capability is made accessible in a number of ways, including power factor control (reactive power is proportional to real power) and volt-var control (reactive power varies according to the local voltage). The test results for these functions are shown in Figure 5-9 and Figure 5-10.

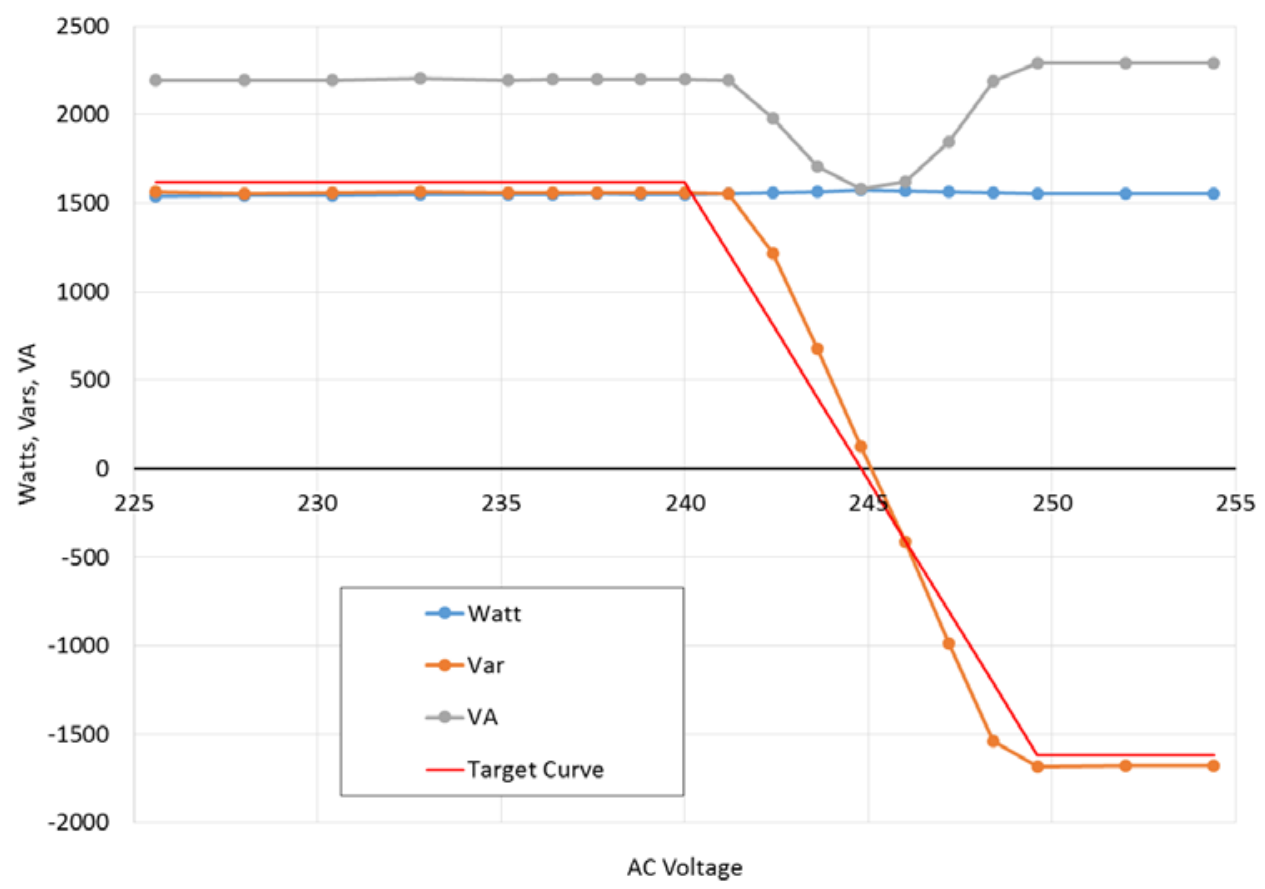

Figure 5-11. Solar Inverter Volt-Var Function 


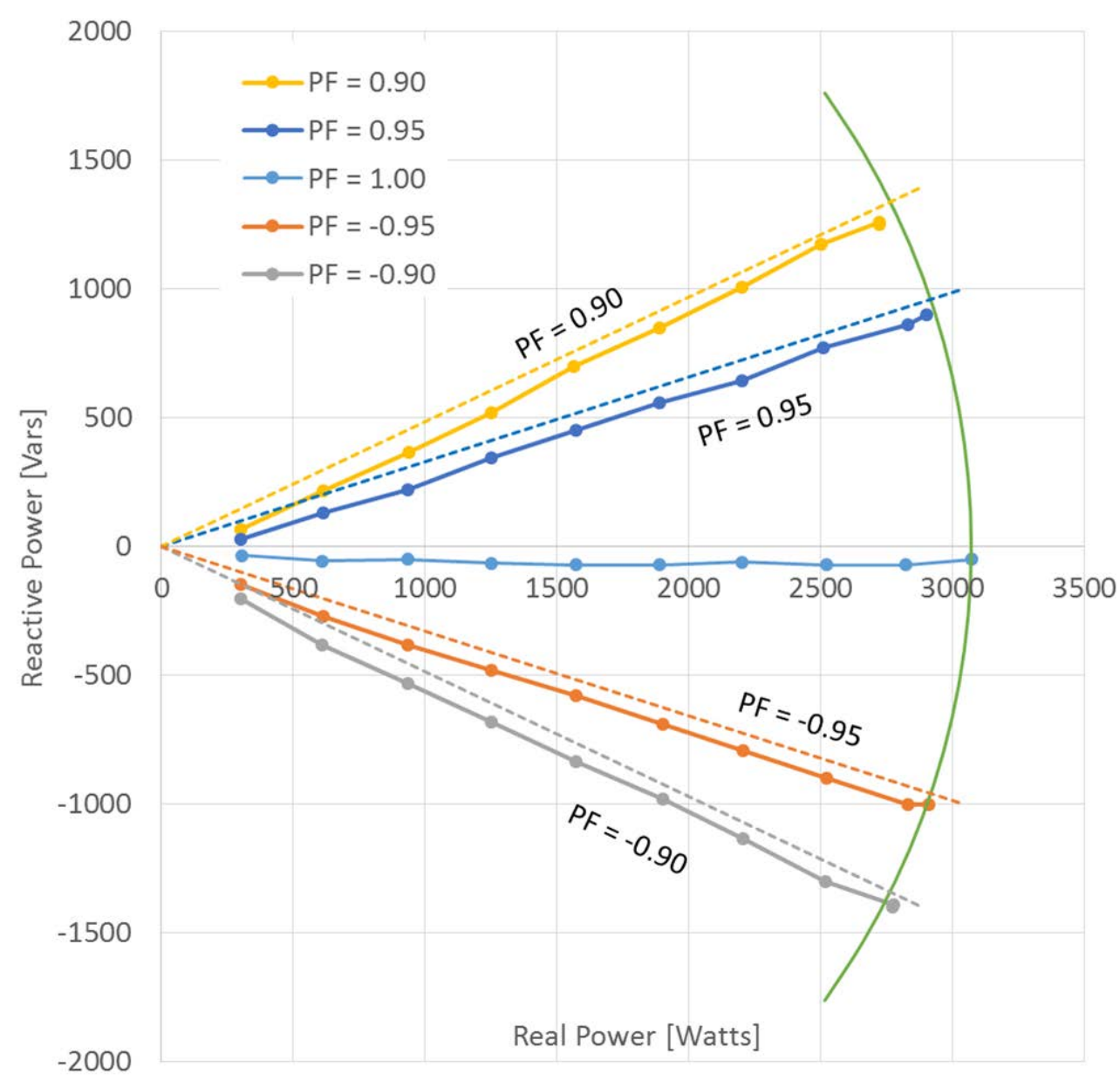

Figure 5-12. Solar Inverter Power Factor Function Measured (solid lines) vs. Ideal (dashed lines)

The inverter's reactive power output had an offset of approximately 75 [Vars] as indicated in Figure 5-10. The manufacturer provides settings that can be used to zero-out this offset, if required, after the product is installed to adjust for differences in the impedance at the connection point. This offset was not adjusted during this project.

\subsubsection{PowerHub Battery Energy Storage System Testing}

The battery energy storage unit can be operated in many different modes as identified in Table 5-3 and detailed separately in the full test plan and results. The choice of operating mode at any particular time depends on the end objective of the deployment. In this project, the main goal was accommodating increased use of renewable generation. Therefore, one of the main aims of the battery system is to avoid curtailing PV inverter output. As stated in the PV inverter discussion above, curtailment should be seen as a last resort function for the PV inverter.

The battery energy storage system is able to source and sink both real and reactive power (fourquadrant operation). This capability can be realized via bulk charge/discharge signals or through autonomous regulatory functions such as peak management and load smoothing or through schedule-based functions such as Volt-Var, and Frequency-Watt. Figure 5-11 and Figure 5-12 show representative test results for bulk charge/discharge programming and Frequency-Watt scheduling respectively. The bulk charge/discharge function in Figure 5-11 demonstrates that 
the programmed real power of the unit follows a command signal through step functions that alternate between charging and discharging. Step changes in the real power request are reflected in measured response of the unit as measured by the unit and lab meters. The momentary mismatch between the requested level and the result seen at the left side of the figure was prior to the function activation and can be ignored.

Figure 5-12 shows the unique Frequency-Watt performance capabilities of a battery storage system in which the unit responds to measured line frequency, charging when frequency is high and discharging when frequency is low. As the reference line frequency increases - indicating that the net local load is relatively low - the battery system increases the net load by charging the battery. As the local load increases, the line frequency may decrease and therefore the battery responds by discharging, reducing the net local load.

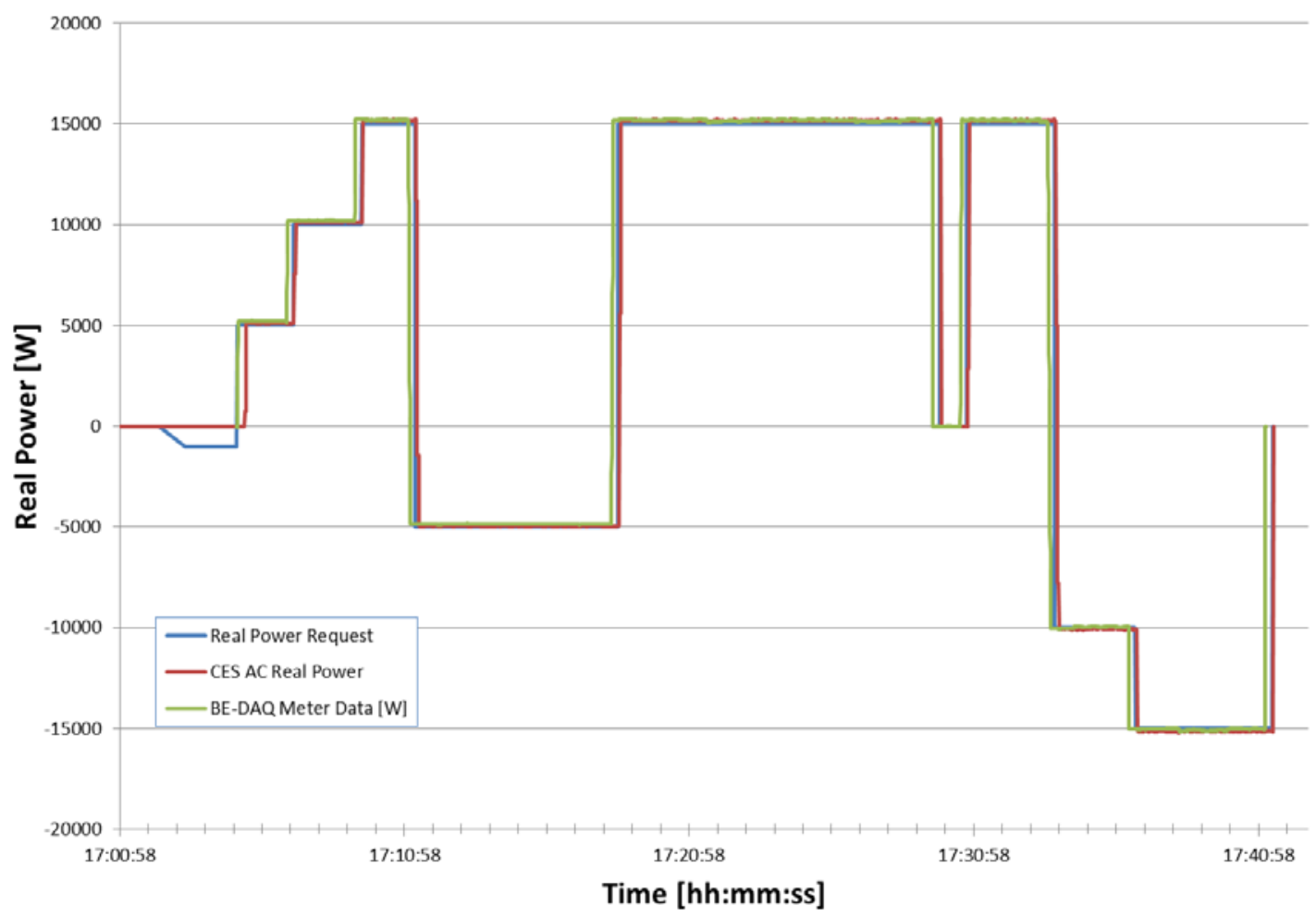

Figure 5-13. Battery System Charge/Discharge Function 


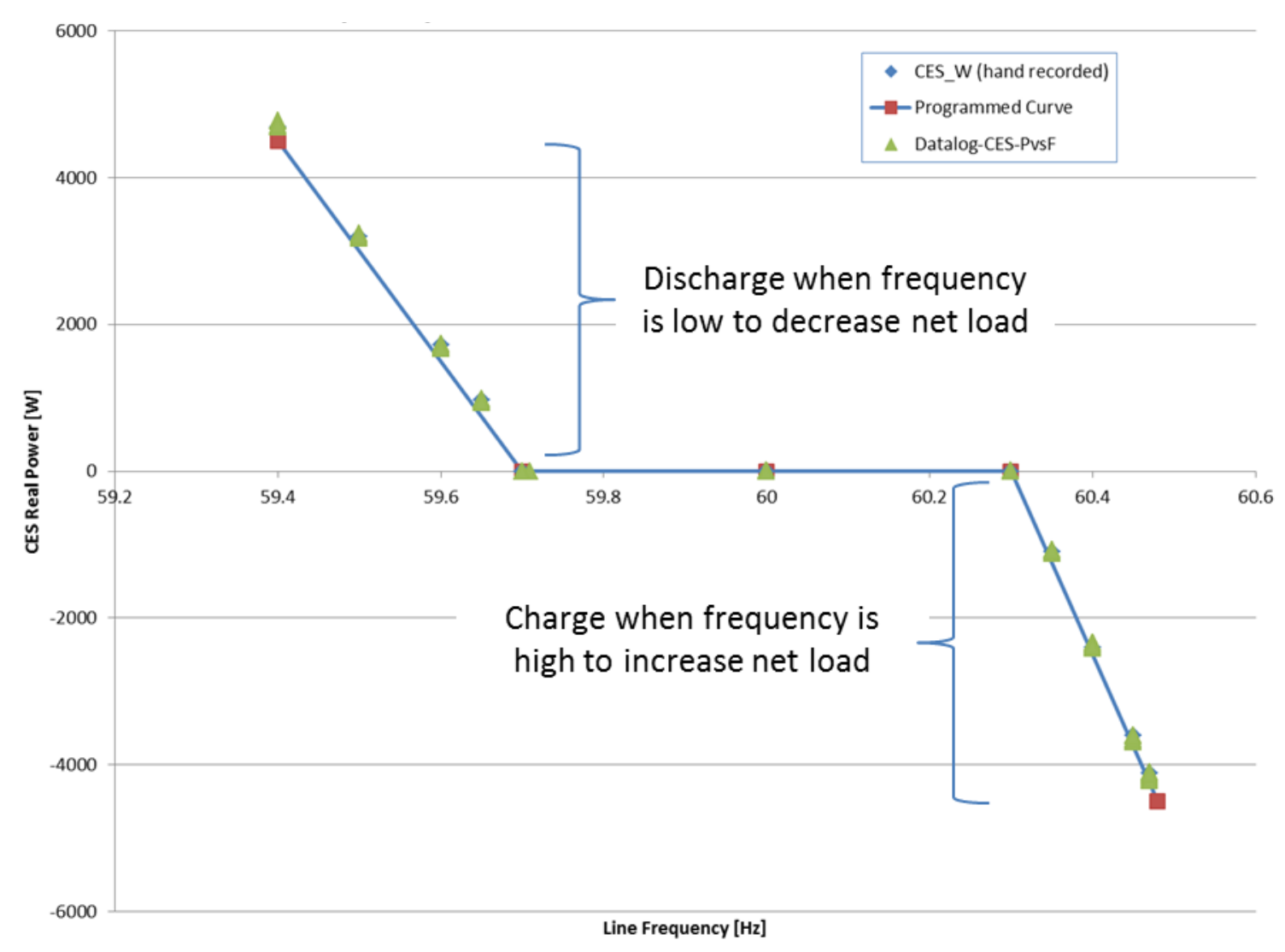

Figure 5-14. Battery System Frequency-Watt Function

\subsection{Summary of Final End-Device Functionality}

Table 5-3 summarizes the functions that each end device supported as of the end of the project. Each product type is unique in terms of its abilities to contribute and has particular strengths to offer in regard to enabling more clean energy on the grid. Utilized collectively, the set of products can provide a highly-flexible resource, working together to help achieve clean energy goals. 
Table 5-7. Summary of End-Device Functions

\begin{tabular}{|c|c|c|c|c|c|c|c|}
\hline Function & $\underset{\text { m }}{\operatorname{m}}$ & 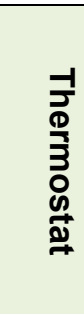 & $\begin{array}{l}\mathbf{D} \\
8 \\
0 \\
0 \\
\frac{0}{3} \\
\frac{5}{0}\end{array}$ & 工市 & 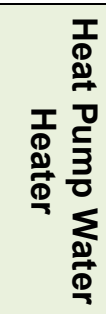 & $\begin{array}{l}\text { ஹ } \\
\text { 음 } \\
\frac{1}{3} \\
\frac{\Phi}{7} \\
\frac{\Phi}{7}\end{array}$ & 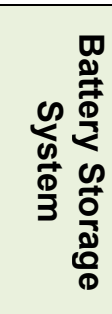 \\
\hline Monitoring Operating State & $\checkmark$ & $\checkmark$ & $\checkmark$ & $\checkmark$ & $\checkmark$ & $\checkmark$ & $\checkmark$ \\
\hline Monitoring Real Power & $\checkmark_{\mathrm{m}}$ & $\checkmark_{s}$ & $\checkmark_{\mathrm{m}}$ & $\checkmark_{\mathrm{e}}$ & $\checkmark_{\mathrm{e}}$ & $\checkmark_{\mathrm{m}}$ & $\checkmark_{\mathrm{m}}$ \\
\hline Monitoring Reactive Power & & & & & & $\checkmark$ & $\checkmark$ \\
\hline Monitoring Frequency & & & & & & $\checkmark$ & $\checkmark$ \\
\hline Monitoring Voltage & & & & & & $\checkmark$ & $\checkmark$ \\
\hline Monitoring Energy-Take Capability & & & $\checkmark$ & $\checkmark$ & $\checkmark$ & & $\checkmark$ \\
\hline $\begin{array}{l}\text { Shed (Moderate Real Power } \\
\text { Curtailment) }\end{array}$ & $\checkmark$ & $\checkmark$ & $\checkmark$ & $\checkmark$ & $\checkmark$ & & \\
\hline $\begin{array}{l}\text { Critical Peak (Aggressive Real } \\
\text { Power Curtailment) }\end{array}$ & $\checkmark$ & $\checkmark$ & $\checkmark$ & $\checkmark$ & $\checkmark$ & & \\
\hline Load-Up (Real Power Increase) & $\checkmark$ & $\checkmark$ & $\checkmark$ & $\checkmark$ & $\checkmark$ & & \\
\hline Variable Real Power Control & $\checkmark$ & & $\checkmark$ & & & $\checkmark$ & $\checkmark$ \\
\hline Power Factor Function & & & & & & $\checkmark$ & $\checkmark$ \\
\hline Volt-Var Function & & & & & & $\checkmark$ & $\checkmark$ \\
\hline Volt-Watt Function & & & & & & $\checkmark$ & $\checkmark$ \\
\hline Watt-Frequency Function & & & & & & $\checkmark$ & $\checkmark$ \\
\hline Scheduled Operation & $\checkmark$ & $\checkmark$ & $\checkmark$ & & & & $\checkmark$ \\
\hline
\end{tabular}

$\mathrm{m}=$ measured via internal metering, $\mathrm{e}=$ device estimate, $\mathrm{s}=$ statistical estimate 


\section{Project Conclusions and Key Take-Aways}

Connected devices are capable of providing grid support to enable more clean energy. There is not a technology gap. Modern products of all types are increasingly micro-processor based and have the potential to provide a wide range of grid-supportive services.

Smart, connected products are a significant step-up in complexity for manufacturers of conventional equipment. The price-sensitive marketplace for many consumer load devices drives designs toward very simple implementations. Accordingly, the skill sets of staff and the palette of ready-technology components often does not map well to the higher-tech demands of communication-enabled, smart devices. This is a challenge for manufacturers. The modular approach of the CTA-2045 interface used on some products during this project helped, by allowing the device manufacturer to not have to gain proficiency in the wide range of communication technologies that may be required.

Open standards are sufficient to enable connected devices to be monitored and managed effectively. The device capabilities that were identified in this project were found to be supportable using communication standards relevant to the device type: CTA-2045 for loads/appliances, SunSpec (Modbus/RTU) for residential solar inverters, and both DNP3 AN 2013-001 and SunSpec (Modbus/TCP) for larger scale battery energy storage. In no case did a limitation of the standard impede the implementation, and although it was expected that the project would identify gaps and aid the ongoing work of the related standards organizations, no such gaps were noted in this project.

Connected devices that provide grid supportive functionality are not commonly available or deployed. While the developments and testing of this project showed the possibility of such features, it is noted that none are a mainstream, or high-volume product of the manufacturer. A primary reason is the incremental cost of adding communication interfaces and functionality to the products. Even in keeping with the low-cost design principle followed in this project (see Chapter 3), there is some marginal cost increase that must be overcome. Having the manufacturer participate actively in the testing is useful in this regard because they are able to quantify their system impact for ancillary uses that could help develop additional compensation schemes.

The incremental cost challenge is inseparably tied to the level of consumer interest and/or utility incentives for such products. Once the overall value of connected devices exceeds the incremental cost, mainstream market demand can follow.

A customer-first approach is required. Both the utilities and manufacturers involved in the project emphasized the importance of putting the consumer's comfort and control first. This priority manifested itself in the form of local settings such as water and room temperature setpoints and offsets, pool pump and EV charging schedules, event override/opt out, and "smart" responses.

A limited number of device capabilities can serve an unlimited number of grid needs. The process followed during this project began with the identification of grid challenges and problems that occur with high-penetration renewables. During this process, it was recognized that the range of such issues is essentially unlimited when studied in detail. For example, the general idea of an overloaded or stressed asset can be broken down into an extensive list of 
potentially impacted devices owned by the consumer or the utility, including circuit breakers, wires, transformers and control equipment.

In contrast to the wide range of grid needs, the number of specific actions required of the end devices was limited. This is an important finding because it means that relatively simple devices and relatively simple protocols can be used to address a wide and complex set of grid issues. During operation, the end devices typically will not know, and do not need to know, "why" they are performing a certain action, they only need to know "what" action is requested.

Smart responses show promise in terms of making grid-supportive devices more acceptable to consumers. The historical alternative to connected load devices is to cut power off using a load control switch. This form of control is "blind" in that it is done with little or no awareness of the state of the end device and leaves the end-device without power to protect consumer comfort. In contrast, where possible the functions designed and demonstrated in this project were "smart" in that the devices responded to control requests to the extent possible, while acting (operating) as needed to ensure that certain comfort and safety limits are not exceeded. What this means to a grid operator is that a greater benefit can be achieved across the population of devices.

While the demonstrated "smart" responses are a step forward from what is achievable with blind load control switches, more improvement is possible. For example, communication standards have been developed for electric vehicles that include scheduled "target state of charge" parameters used to ensure that the vehicle is ready when the consumer needs it. Presently, vehicle manufacturers have not made these standards available on the connection to the EVSE.

Connected devices make it possible for consumers to tailor responses to meet their needs. Traditional load control programs used switches to shut-off products entirely. This produced a consistent, predictable response, but didn't allow for consumers to tailor responses to meet their personal interests and therefore limited consumer willingness to participate in DR programs. Connected devices make this possible, either through device-level customization or through automation/control systems that the consumer manages.

- Example of tailoring responses at the device-level: Temperature offsets that were applied by the thermostat upon receipt of Shed or Critical Peak event signals used default values of 4 and 8 degrees respectively. But the consumer could adjust these to different values to suit their interests. Some have referred to this as a "Comfort vs. Savings" adjustment.

- Example of tailoring responses at the control/automation system: Products such as those demonstrated in this project can be connected to home automation systems that allow the consumer to define how they want their devices to respond. For example, a curtailment signal or high-price signal could be received from the utility by a home energy management system. This system, acting based on a configuration chosen by the consumer, could then manage each device as desired, monitoring present conditions and using duty-cycles, durations, and variable power levels accordingly. If a consumer doesn't want their water heater to respond unless it is within 800 [Wh] of maximum storage, then it wouldn't.

Such adjustability complicates the process of placing a value on a given product, but the monitoring capabilities demonstrated make it possible to assess the degree of response and controllability. 
Advanced status monitoring of connected devices significantly enhances value. All the devices involved in the project provided real-time status monitoring. In addition to the present status (e.g. power level), some provided an indicator of their present ability to absorb energy. For example:

- Water heaters can make computations based on existing internal temperature sensors to determine the amount of energy (Watt-hours) they can absorb

- Electric vehicle chargers can use historical data to estimate forward-looking energy-take capability

- Pool pumps can assess their programmed schedules and current activity to determine how much remaining energy-take capability is available at any time

- Battery storage systems can directly assess state-of-charge to determine their ability to absorb energy

Aggregated across populations of devices, this parameter can provide grid-operators or other load management systems with a real-time measure of the size of resource that exists at a given time. To use the analogy of a pumped hydro system, the power reading of the connected devices is like the power rating of the pumped hydro system (Watts), but the Energy-Take reading is like the remaining water-storage capacity of the reservoir. In this way, operators could know not just the rate at which the population of devices can take energy, but for how long this rate can be sustained before the resource is depleted.

A certification processes is needed in order for communication interfaces to be consistent. In this project, manufacturers used a set of tools provided by EPRI and the SunSpec Alliance to help in the development of their products. This helped to ensure a consistent interpretation of the standards and uniformity of the interfaces. To achieve such results going forward and in a much broader market, precise communication certification processes will be required.

Mitigation of clean energy issues will benefit from devices at multiple levels. Various goals and use cases may be addressed at different levels in the power system. For example:

- Limiting load on a distribution transformer: When several homes are fed from the same distribution transformer, each may have different types of connected devices such as a swimming pool pump, a solar inverter, and an electric vehicle charger. The set of devices may be used in conjunction with a battery storage system at the transformer and by working together, the quantity of storage required to meet the goal might be reduced.

- Limiting peak demand at the consumer level: If a consumer is on a rate plan that includes demand charges, then upstream equipment on the utility side of the meter will not help. Connected devices within the home, possibly coordinated via a home energy management system, are needed to meet goals at the premises-level.

The PowerHub Systems battery energy storage system was unique among the devices in the project in that it would typically be deployed at the level of the distribution transformer representing multiple homes. The functional requirements identified for this device envisioned working together with the end devices, supplementing their actions. 